Supporting Information for:

\title{
Metal-Diamidobenzoquinone Frameworks via Post-Synthetic Linker Exchange
}

\author{
Lujia Liu, Liang Li, Michael E. Ziebel, and T. David Harris* \\ Departments of Chemistry, \\ Northwestern University, 2145 Sheridan Road, Evanston, Illinois 60208, USA \\ University of California, Berkeley, California 94720, USA
}

Email: dharris@berkeley.edu

J. Am. Chem. Soc.

\section{Table of Contents}

Experimental Section

Table S1 | Crystallographic data for 2-6

Table S2 | EDX spectra for 5 (batch 1)

Table S3 | EDX spectra for 5 (batch 2)

S11

Table S4 | EDX spectra for 5 (batch 3)

S13

Table S5 | EDX spectra for 5 (batch 4)

S15

Figure S1 | Crystal structure of 4

S17

Figure S2 | Crystal structure of $\mathbf{2}$

S18

Figure S3 | Crystal structure of $\mathbf{3}$

S19

Figure S4 | Crystal structure of 5

S20

Figure S5 | Crystal structure of 6

S21

Figure S6 | Experimental and simulated PXRD patterns for 2

S22

Figure S7 | Experimental and simulated PXRD patterns for 3

S23

Figure S8 | Experimental and simulated PXRD patterns for 5

S24

Figure S9 | Experimental and simulated PXRD patterns for $\mathbf{6}$

S25

Figure S10 $\mid{ }^{13} \mathrm{C}$ NMR spectrum for $\mathbf{2}$

S26 
Figure S11 $\mid{ }^{13} \mathrm{C}$ NMR spectrum for $3 \quad$ S27

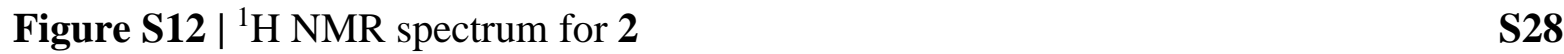

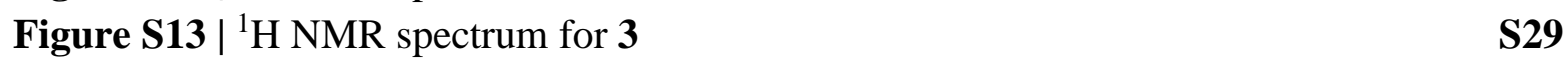

Figure S14 | EDX spectrum for $5 \quad \mathbf{S 3 0}$

Figure S15 $\mid{ }^{13} \mathrm{C}$ NMR spectrum for $\mathrm{CH}_{2} \mathrm{Cl}_{2}$-activated 5

Figure S16 | SEM and EDX mapping images of 5 (batch 1) $\quad$ S32

Figure S17 | SEM and EDX mapping images of 5 (batch 2)

Figure S18 | SEM and EDX mapping images of 5 (batch 3) $\quad \mathbf{S 3 4}$

Figure S19 | SEM and EDX mapping images of 5 (batch 4)

Figure S20 | SEM and EDX mapping images of 5 (batch 5) $\quad$ S36

$\begin{array}{ll}\text { Figure S21 | Acid-base titration curves for ligands } & \text { S37 }\end{array}$

Figure S22 | PXRD patterns for 1, 3, and an intermediate product $\quad \mathbf{S 3 8}$

Figure S23 | Proposed mechanism for linker exchange $\quad$ S39

Figure S24 | $\mathrm{N}_{2}$ adsorption and desorption isotherms at $77 \mathrm{~K} \quad \mathbf{S 4 0}$

Figure S25 | Consistency plots for calculating BET surface area of $\mathbf{1} \quad \mathbf{S 4 1}$

References $\quad \mathbf{S 4 2}$ 


\section{Experimental Section}

General Considerations. Unless otherwise specified, chemicals and solvents were purchased from commercial vendors and used without further purification. Deuterated solvents were purchased from Cambridge Isotope Laboratories. Dichloromethane (DCM) and benzene were dried using a commercial solvent purification system from Pure Process Technology. Water was obtained from a purification system from EMD Millipore. The compound $\left(\mathrm{Me}_{2} \mathrm{NH}_{2}\right)_{2}\left[\mathrm{Zn}_{2} \mathrm{~L}_{3}\right]$ (1) was prepared according a literature procedure. ${ }^{1}$ Elemental analysis was conducted by Midwest Microlab Inc. or Integrated Molecular Structure Education and Research Center (IMSERC) at Northwestern University.

2,5-Diamino-3,6-Dibromo-1,4-Benzoquinone $\left(\mathbf{H}_{2}{ }^{\mathrm{Br}} \mathbf{L}^{\prime}\right){ }^{2}$ In a $250 \mathrm{~mL}$ round bottom flask, 2,3,5,6-tetrabromo-1,4-benzoquinone ( $p$-bromanil, $25 \mathrm{~g}$, $59 \mathrm{mmol}$ ) was suspended in ethanol (150 $\mathrm{mL})$. The resulting suspension was heated to $60{ }^{\circ} \mathrm{C}$ and $\mathrm{NH}_{4} \mathrm{OH}(30 \%, 200 \mathrm{~mL})$ was added dropwise. The reaction mixture was heated at reflux for another $12 \mathrm{~h}$. The brown solid was isolated by filtration, washed with water $(200 \mathrm{~mL})$, ethanol $(200 \mathrm{~mL})$, and diethyl ether $(200 \mathrm{~mL})$, and dried under reduced pressure to afford the title compound as a brown crystalline solid. Yield: 9.4 $\mathrm{g}(54 \%){ }^{13} \mathrm{C}$ NMR (125 MHz, DCl/DMSO-d 6$): \delta 170.12(\mathrm{C}=\mathrm{O}), 150.55(\mathrm{C}-\mathrm{N}), 90.17$ (C-Br) ppm.

2,5-Diamino-3,6-Dichloro-1,4-Benzoquinone $\left(\mathbf{H}_{2}{ }^{\mathrm{Cl}_{\mathbf{L}}} \mathbf{L}^{\prime}\right){ }_{0}^{3} \quad$ 2,3,5,6-tetrachloro-1,4-benzoquinone ( $p$-chloranil, $23 \mathrm{~g}, 94 \mathrm{mmol}$ ) was suspended in methoxyethyl acetate $(90 \mathrm{~mL})$. The resulting yellow turbid suspension was heated to $60{ }^{\circ} \mathrm{C}$ and ammonium hydroxide $(30 \%, 36 \mathrm{~mL})$ was dropped slowly to the mixture. The reaction mixture was then kept at $80^{\circ} \mathrm{C}$ for $1 \mathrm{~h}$ before cooled to room temperature and stirred for another $24 \mathrm{~h}$. The brown solid was filtered, washed with water (100 $\mathrm{mL})$ and acetone $(50 \mathrm{~mL})$, and dried under reduced pressure to afford the title compound as a brown crystalline solid. Yield $19 \mathrm{~g}(98 \%) .{ }^{13} \mathrm{C}$ NMR (125 MHz, DCl/DMSO-d 6$) \delta 170.13(\mathrm{C}=\mathrm{O})$, 148.67 (C-N), 99.41 (C-Cl) ppm.

$\left(\mathbf{E t}_{4} \mathbf{N}\right)_{2}\left[Z_{2} \mathbf{L}_{1.3}{ }^{\left.\mathrm{Br} \mathbf{L}^{\prime}{ }_{1.7}\right] \cdot 0.57 D M F \cdot 0.14 E t_{2}} \mathrm{O}\right.$ (2). In a $20 \mathrm{~mL}$ scintillation vial, $\left(\mathrm{NEt}_{4}\right) \mathrm{OH}(0.828$ $\mathrm{mL}, 40 \%$ wt. in $\mathrm{H}_{2} \mathrm{O}, 2.25 \mathrm{mmol}$ ) was added to a brown suspension of 2,5-diamino-3,6dibromobenzoquinone $\left(\mathrm{H}_{2}{ }^{\mathrm{Br}} \mathrm{L}^{\prime}, 665 \mathrm{mg}, 2.25 \mathrm{mmol}\right)$ in DMF $(15 \mathrm{~mL})$ to form a dark purple solution. Purple hexagonal crystals of $\left(\mathrm{Me}_{2} \mathrm{NH}_{2}\right)_{2}\left[\mathrm{Zn}_{2} \mathrm{~L}_{3}\right](1,41 \mathrm{mg}, 50 \mu \mathrm{mol})$ standing in DMF $(0.5 \mathrm{~mL})$ were then added to this solution. The resulting mixture was heated to $75{ }^{\circ} \mathrm{C}$ in a heating block for $48 \mathrm{~h}$. The supernatant was decanted while the reaction mixture was still hot. Fresh, ambient-temperature DMF (5 mL) was immediately added to the residual solid. At ambient temperature, this decanting-replenishing procedure was repeated 10 times, until the supernatant became colorless. The supernatant was again decanted and fresh $\mathrm{Et}_{2} \mathrm{O}(5 \mathrm{~mL})$ was added. This decanting-replenishing procedure was repeated 5 more times. After the final decanting of the supernatant, the residual solid product was heated to $100{ }^{\circ} \mathrm{C}$ under dynamic vacuum (4 mTorr) for $16.5 \mathrm{~h}$ to afford the title product as red hexagonal crystals. Yield: $60 \mathrm{mg}(98 \%) .{ }^{1} \mathrm{H}$ NMR $(500$ MHz, DCl/DMSO- $d_{6}$, see Figure S12): $\delta 8.02$ (s, $\mathrm{H}_{2}{ }^{\mathrm{Br}} \mathrm{L}^{\prime}$ ), 7.85 (s, DMF), $3.85\left(\mathrm{~s}, \mathrm{H}_{2}{ }^{\mathrm{Br}} \mathrm{L}^{\prime}\right), 3.71$ $\left(\mathrm{H}_{3} \mathrm{O}^{+}\right), 3.37\left(\mathrm{q}, J=6.9 \mathrm{~Hz}, \mathrm{Et}_{2} \mathrm{O}\right), 3.20\left(\mathrm{q}, J=7.4 \mathrm{~Hz}, \mathrm{Et}_{4} \mathrm{~N}^{+}\right), 2.88(\mathrm{~s}, \mathrm{DMF}), 2.72$ (s, DMF), 1.15 $\left(\mathrm{tt}, J=7.4 \mathrm{~Hz}, \mathrm{Et}_{4} \mathrm{~N}^{+}\right), 1.08\left(\mathrm{t}, J=6.9 \mathrm{~Hz}, \mathrm{Et}_{2} \mathrm{O}\right) \mathrm{ppm} .{ }^{13} \mathrm{C} \mathrm{NMR}\left(125 \mathrm{MHz}, \mathrm{DCl} / \mathrm{DMSO}-d_{6}\right.$, see Figure S10) $\delta 170.1\left(\mathrm{H}_{2}{ }^{\mathrm{Br}} \mathrm{L}^{\prime}, \mathrm{C}=\mathrm{O}\right), 165.8\left(\mathrm{H}_{2} \mathrm{~L}, \mathrm{C}=\mathrm{O}\right), 162.5(\mathrm{DMF}), 150.6\left(\mathrm{H}_{2}{ }^{\mathrm{Br}} \mathrm{L}^{\prime}, \mathrm{C}-\mathrm{N}\right), 109.1$ $\left(\mathrm{H}_{2} \mathrm{~L}, \mathrm{C}-\mathrm{Cl}\right), 90.2\left(\mathrm{H}_{2}{ }^{\mathrm{Br}} \mathrm{L}^{\prime}, \mathrm{C}-\mathrm{Br}\right), 65.0\left(\mathrm{Et}_{2} \mathrm{O}\right), 51.5\left(\mathrm{Et}_{4} \mathrm{~N}^{+}\right), 35.9(\mathrm{DMF}), 30.9\left(\mathrm{DMF}^{2}\right), 15.3\left(\mathrm{Et}_{2} \mathrm{O}\right)$, 
7.1 $\left(\mathrm{Et}_{4} \mathrm{~N}^{+}\right)$ppm. Anal. Calcd. for $\left[\mathrm{C}_{36.27} \mathrm{H}_{48.79} \mathrm{Br}_{3.4} \mathrm{Cl}_{2.6} \mathrm{~N}_{5.97} \mathrm{O}_{9.31} \mathrm{Zn}_{2}\right]$ : C, 35.94; H, 4.06; N, $6.90 \%$. Found: C, 36.49; H, 4.56; N, 7.25\%.

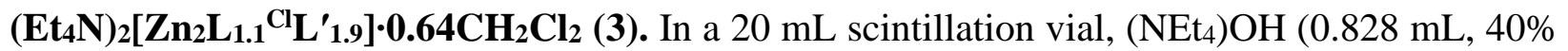
wt. in $\left.\mathrm{H}_{2} \mathrm{O}, 2.25 \mathrm{mmol}\right)$ was added to a brown suspension of 2,5-diamino-3,6dichlorobenzoquinone $\left(\mathrm{H}_{2}{ }^{\mathrm{Cl}} \mathrm{L}^{\prime}, 466 \mathrm{mg}, 2.25 \mathrm{mmol}\right)$ in $\mathrm{DMF}(15 \mathrm{~mL})$ to form a dark purple solution. Purple hexagonal crystals of $\left(\mathrm{Me}_{2} \mathrm{NH}_{2}\right)_{2}\left[\mathrm{Zn}_{2}(\mathrm{~L})_{3}\right](1,41 \mathrm{mg}, 50 \mu \mathrm{mol})$ standing in DMF $(0.5 \mathrm{~mL})$ were then added to this solution. The resulting mixture was heated to $75^{\circ} \mathrm{C}$ in a heating block for $48 \mathrm{~h}$. The supernatant was decanted while the reaction mixture was still hot. Fresh, ambient-temperature DMF $(5 \mathrm{~mL})$ was immediately added to the residual solid. At ambient temperature, this decanting-replenishing procedure was repeated 10 times, until the supernatant became colorless. The supernatant was again decanted and fresh $\mathrm{CH}_{2} \mathrm{Cl}_{2}(5 \mathrm{~mL})$ was added. This decanting-replenishing procedure was repeated 5 more times. After the final decanting of the supernatant, the residual solid product was heated to $100{ }^{\circ} \mathrm{C}$ under dynamic vacuum (4 mTorr) for $2 \mathrm{~h}$ to afford the title product as red hexagonal crystals. Yield: $50 \mathrm{mg}(97 \%) .{ }^{1} \mathrm{H} \mathrm{NMR}(500 \mathrm{MHz}$, DCl/DMSO-d 6 , see Figure S13): $\delta 8.01\left(\mathrm{~s}, \mathrm{H}_{2}{ }^{\mathrm{Cl}} \mathrm{L}^{\prime}\right), 8.00\left(\mathrm{~s}, \mathrm{H}_{2}{ }^{\mathrm{Cl}} \mathrm{L}^{\prime}\right), 5.75\left(\mathrm{~s}, \mathrm{CH}_{2} \mathrm{Cl}_{2}\right), 3.20(\mathrm{q}, J=$ $\left.7.4 \mathrm{~Hz}, \mathrm{Et}_{4} \mathrm{~N}^{+}\right), 1.16\left(\mathrm{tt}, J=7.4 \mathrm{~Hz}, \mathrm{Et}_{4} \mathrm{~N}^{+}\right) \mathrm{ppm} .{ }^{13} \mathrm{C} \mathrm{NMR}\left(125 \mathrm{MHz}, \mathrm{DCl} / \mathrm{DMSO}-\mathrm{d}_{6}\right.$, see Figure S11) $\delta 170.1\left(\mathrm{H}_{2}{ }^{\mathrm{Cl}} \mathrm{L}^{\prime}, \mathrm{C}=\mathrm{O}\right), 165.7\left(\mathrm{H}_{2} \mathrm{~L}, \mathrm{C}=\mathrm{O}\right), 148.7\left(\mathrm{H}_{2}{ }^{\mathrm{Cl}} \mathrm{L}^{\prime}, \mathrm{C}-\mathrm{N}\right), 108.7\left(\mathrm{H}_{2} \mathrm{~L}, \mathrm{C}-\mathrm{Cl}\right), 99.4$ $\left(\mathrm{H}_{2}{ }^{\mathrm{Cl}} \mathrm{L}^{\prime}, \mathrm{C}-\mathrm{Cl}\right), 54.9\left(\mathrm{CH}_{2} \mathrm{Cl}_{2}\right), 51.4\left(\mathrm{Et}_{4} \mathrm{~N}^{+}\right), 7.1\left(\mathrm{Et}_{4} \mathrm{~N}^{+}\right)$ppm. For combustion elemental analysis, the crystals were further heated at $100{ }^{\circ} \mathrm{C}$ under dynamic vacuum (4 mTorr) for 14 hours to afford a solvent-free sample with a formula of $\left(\mathrm{Et}_{4} \mathrm{~N}\right)_{2}\left[\mathrm{Zn}_{2}(\mathrm{~L})_{1.1}\left({ }^{\mathrm{Cl}} \mathrm{L}^{\prime}\right)_{1.9}\right]$. Anal. Calcd. for $\left[\mathrm{C}_{34} \mathrm{H}_{43.8} \mathrm{Cl}_{6} \mathrm{~N}_{5.8} \mathrm{O}_{8.2} \mathrm{Zn}_{2}\right]$ : C, 40.50; H, 4.38; N, $8.06 \%$. Found: C, 40.41; H, 4.69; N, $7.88 \%$.

$\left(\mathbf{M e}_{2} \mathbf{N H}_{2}\right)_{2}\left[\mathrm{Mn}_{2} \mathrm{~L}_{3}\right]$ (4). To a solid mixture of $\mathrm{Mn}\left(\mathrm{NO}_{3}\right)_{2} \cdot 4 \mathrm{H}_{2} \mathrm{O}$ (4.0 g, $\left.16 \mathrm{mmol}\right)$ and chloranilic acid $\left(\mathrm{H}_{2} \mathrm{~L}, 6.6 \mathrm{~g}, 32 \mathrm{mmol}\right)$ in a $100 \mathrm{~mL}$ Schott bottle, DMF $(80 \mathrm{~mL})$ and $\mathrm{H}_{2} \mathrm{O}(2.3 \mathrm{~mL})$ were added. The resulting mixture was shaken until most of the solid dissolved, and the reaction was placed in an isothermal oven at $130{ }^{\circ} \mathrm{C}$ for $16 \mathrm{~h}$. After the reaction mixture was cooled to ambient temperature, the mother liquor was decanted and then replenished with fresh DMF (50 mL). This decanting-replenishing procedure was repeated 10 times, until the supernatant became colorless. The supernatant was again decanted and fresh $\mathrm{CH}_{2} \mathrm{Cl}_{2}(50 \mathrm{~mL})$ added. This decanting-replenishing procedure was repeated 5 more times. After final decanting of the supernatant, the residual solid product was heated to $100{ }^{\circ} \mathrm{C}$ under dynamic vacuum (4 mTorr) for 16.5 hours to afford the title product as brown hexagonal crystals. Yield: $3.1 \mathrm{~g}(47 \%)$. Anal. Calcd. for $\left[\mathrm{C}_{22} \mathrm{H}_{16} \mathrm{Cl}_{6} \mathrm{Mn}_{2} \mathrm{~N}_{2} \mathrm{O}_{12}\right]$ : C, 32.11; H, 1.96; N, $3.40 \%$. Found: C, 32.06; H, 2.21; N, $3.39 \%$.

$\left(\mathbf{E t}_{4} \mathbf{N}\right)_{2}\left[\mathbf{M n}_{2} \mathbf{L}_{1.8}{ }^{\mathrm{Br}^{2}} \mathbf{L}_{1.2}{ }_{1.2} \cdot \mathbf{0 . 6 5 D M F} \text { (5). In a } 20 \mathrm{~mL} \text { scintillation vial, (NEt }\right)_{4} \mathrm{OH}(0.828 \mathrm{~mL}, 40 \%$ wt. in $\left.\mathrm{H}_{2} \mathrm{O}, 2.25 \mathrm{mmol}\right)$ was added to a brown suspension of 2,5-diamino-3,6dibromobenzoquinone $\left(\mathrm{H}_{2}{ }^{\mathrm{Br}} \mathrm{L}^{\prime}, 665 \mathrm{mg}, 2.25 \mathrm{mmol}\right)$ in DMF $(15 \mathrm{~mL})$ to form a dark purple solution. Brown hexagonal crystals of $\left(\mathrm{Me}_{2} \mathrm{NH}_{2}\right)_{2}\left[\mathrm{Mn}_{2} \mathrm{~L}_{3}\right](4,41 \mathrm{mg}, 50 \mu \mathrm{mol})$ standing in DMF $(0.5 \mathrm{~mL})$ were then added to this solution. The resulting mixture was heated to $75{ }^{\circ} \mathrm{C}$ in a heating block for $48 \mathrm{~h}$. The supernatant was decanted while the reaction mixture was still hot. Fresh, ambient-temperature DMF $(5 \mathrm{~mL})$ was immediately added to the residual solid. At ambient temperature, this decanting-replenishing procedure was repeated 10 times, until the supernatant became colorless. The supernatant was again decanted and fresh $\mathrm{CH}_{2} \mathrm{Cl}_{2}(5 \mathrm{~mL})$ was added. This 
decanting-replenishing procedure was repeated 5 more times. After the final decanting of the supernatant, the residual solid product was heated to $80^{\circ} \mathrm{C}$ under dynamic vacuum (49 mTorr) for $12 \mathrm{~h}$ to afford the title product as brown hexagonal crystals. Yield: $53 \mathrm{mg}$ (97\%). Anal. Calcd. for $\left[\mathrm{C}_{35.95} \mathrm{H}_{46.95} \mathrm{Br}_{2.4} \mathrm{Cl}_{3.6} \mathrm{Mn}_{2} \mathrm{~N}_{5.05} \mathrm{O}_{10.25}\right]: \mathrm{C}, 37.77 ; \mathrm{H}, 4.14 ; \mathrm{N}, 6.19 \%$. Found: $\mathrm{C}, 37.70 ; \mathrm{H}, 4.21 ; \mathrm{N}$, $6.19 \%$.

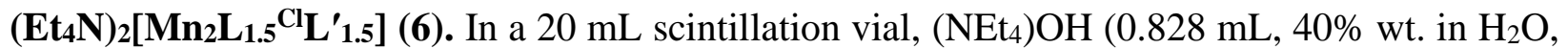
$2.25 \mathrm{mmol})$ was added to a brown suspension of 2,5-diamino-3,6-dichlorobenzoquinone $\left(\mathrm{H}_{2}{ }^{\mathrm{Cl}} \mathrm{L}^{\prime}\right.$, $466 \mathrm{mg}, 2.25 \mathrm{mmol})$ in DMF (15 mL) to form a dark purple solution. Brown hexagonal crystals of $\left(\mathrm{Me}_{2} \mathrm{NH}_{2}\right)_{2}\left[\mathrm{Mn}_{2} \mathrm{~L}_{3}\right](4,41 \mathrm{mg}, 50 \mu \mathrm{mol})$ standing in DMF $(0.5 \mathrm{~mL})$ were then added to this solution. The resulting mixture was heated to $75{ }^{\circ} \mathrm{C}$ in a heating block for $48 \mathrm{~h}$. The supernatant was decanted while the reaction mixture was still hot. Fresh, ambient-temperature DMF (5 mL) was immediately added to the residual solid. At ambient temperature, this decanting-replenishing procedure was repeated 10 times, until the supernatant became colorless. The supernatant was again decanted and fresh $\mathrm{CH}_{2} \mathrm{Cl}_{2}(5 \mathrm{~mL})$ was added. This decanting-replenishing procedure was repeated 5 more times. After the final decanting of the supernatant, the residual solid product was heated to $100{ }^{\circ} \mathrm{C}$ under dynamic vacuum (5 mTorr) for $13 \mathrm{~h}$ to afford the title product as brown hexagonal crystals. Yield: $48 \mathrm{mg}(97 \%)$. Anal. Calcd. for $\left[\mathrm{C}_{34} \mathrm{H}_{43} \mathrm{Cl}_{6} \mathrm{Mn}_{2} \mathrm{~N}_{5} \mathrm{O}_{9}\right]$ : C, 41.32; H, 4.39; N, $7.09 \%$. Found: C, 41.74; H, 4.77; N, $7.00 \%$.

Single-Crystal X-ray Structure Determination. Single crystals of 2-6 were immersed in DMF to keep the compounds solvated before they were coated with a small amount of Paratone oil for data collection. Data collections were performed on one of the three following Bruker Kappa Apex II diffractometers, all of which are equipped with a Bruker Kappa APEX CCD area detector. The first diffractometer is equipped with a $\mathrm{Cu} \mathrm{K} \alpha$ microfocus source and a MX optics monochromator. The second diffractometer is equipped with a switchable duo source with both $\mathrm{Cu} \mathrm{K} \alpha$ and Mo $\mathrm{K} \alpha$ microfocus sources, both of which are monochromated with a corresponding Quazar optics. The third diffractometer is equipped Mo $\mathrm{K} \alpha$ sealed tube source and a graphite monochromator. The data collections were performed at $100 \mathrm{~K}$ or $250 \mathrm{~K}$. Raw data were integrated, scaled and averaged using the Bruker APEX3 software. ${ }^{4}$ Absorption corrections were applied using SADABS. ${ }^{5}$ Space groups were determined by examination of systematic absence, $E$-statistics using XPREP ${ }^{6}$ and successive refinement of structures. Structures were solved using SHELXT $^{7}$ and refined with SHELXL $^{7}$ using the Olex 2 graphical interface. ${ }^{8}$ All framework atoms were solved and refined anisotropically. For 2, 3, 5, and 6, both diamino- and dihydroxobenzoquinone linkers are disordered by occupying the same lattice sites. To finalize the structure refinements, residual electron densities contributed from disordered solvent molecules and counterions were removed using the solvent mask protocol in Olex $2 .{ }^{8}$ Crystallographic data and the details of data collection are listed in Table S1.

Powder X-ray Diffraction Analyses. Approximately $1 \mathrm{mg}$ of polycrystalline samples were loaded in a hollow metallic sample holder, and both sides were sealed with Kapton tape. A small amount of extra DMF was added to the sample to ensure the samples were kept fully-solvated during the measurement. The powder X-ray diffraction (PXRD) patterns were measured at a transmission geometry using a STOE STADI MP instrument equipped with a $\mathrm{Cu} \mathrm{K} \alpha_{1}$ sealed tube 
source and a $1 \mathrm{D}$ strip detector covering $2 \theta$ range of $6^{\circ}$. The sample holder was spun during the measurement to obtain a better powdered-average.

Raman Spectroscopy and Mapping. Crystals of 1-6 were deposited onto a silicon oxide-coated silicon wafer and sealed in a Linkam THMS350 V microscope stage. Raman spectra were collected using a Horiba LabRam HR Evolution confocal microscope. Individual crystals were excited with a $473 \mathrm{~nm}$ continuous-wave diode laser at $0.236 \mathrm{~mW}$ power equipped with a long working distance $50 \times$ microscope objective ( $\mathrm{NA}=0.50$; Nikon) and 600 grooves $/ \mathrm{mm}$ grating. To perform Raman mapping, a full spectrum at the energy range of 400-2000 $\mathrm{cm}^{-1}$ was collected at each mapping

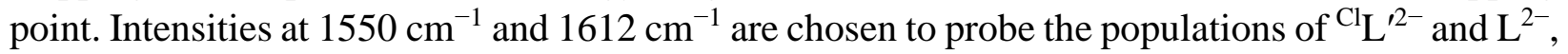
respectively.

Qualitative NMR Spectroscopy. Samples were digested using the following protocol: $23 \mu \mathrm{L}$ of a $35 \% \mathrm{DCl}$ solution in $\mathrm{D}_{2} \mathrm{O}$ was mixed with $1 \mathrm{~mL}$ of DMSO- $d_{6}$ to give a DCl/DMSO- $d_{6}$ stock solution. Approximately $2 \mathrm{mg}$ of compound was digested in $150 \mu \mathrm{L}$ of this stock solution and 450 $\mu \mathrm{L}$ of DMSO- $d_{6} \cdot{ }^{1} \mathrm{H}$ and ${ }^{13} \mathrm{C}$ NMR spectra were then acquired immediately following dissolution using a Bruker Avance III $500 \mathrm{MHz}$ spectrometer equipped with a DCH CryoProbe.

Quantitative ${ }^{13} \mathbf{C}$ NMR Spectroscopy. External ratiometric calibration curves were acquired for $\mathrm{H}_{2} \mathrm{~L} / \mathrm{H}_{2}{ }^{\mathrm{Br}} \mathrm{L}^{\prime}$ and $\mathrm{H}_{2} \mathrm{~L} / \mathrm{H}_{2}{ }^{\mathrm{Cl}} \mathrm{L}^{\prime}$ mixtures with known relative mole ratio. Specifically, qualitative ${ }^{13} \mathrm{C}$ NMR spectra were collected, and peaks were integrated using automatic method with MestReNova software package. Integral regions were detected automatically using Peak Picking algorithm with a minimum area threshold of $3 \%$. Total peak area ratio for the two linkers are plotted against their mole ratios. Then, to quantify linker exchange in $\mathbf{2}$ and $\mathbf{3}$, we integrated the peaks of their qualitative ${ }^{13} \mathrm{C}$ NMR spectra. The total peak area ratio for the two linkers were thus obtained, and linker ratios are found from external radiometric calibration curves.

Scanning Electron Microscopy and Energy Dispersive X-ray Spectroscopy. Desolvated crystals were sprinkled on a double-sided carbon tape which is fixed on a sample holder. To improve the electronic conductivity of the MOF crystals, samples were coated with carbon using a Denton III Desk Sputter Coater or osmium using a SPI Osmium Coater. Scanning electron imaging and EDX analyses were carried out using Hitachi S4800-II cFEG SEM or Hitachi SU8030 SEM. EDX data were acquired and analyzed using the Aztec software package. In the software, the samples were selected to have been coated with $100 \mathrm{~nm}$ of carbon regardless of the actual coating to attenuate the carbon signal to obtain a more accurate quantitation for metal and chlorine. The accelerating voltage was set to $30.0 \mathrm{kV}$ to maximize the penetration. This led to an increase in the interaction volume of the electron beam with the interior of the sample, and therefore the EDX analysis reflected more interior of the sample rather than the outer surface.

Acid-Base Titration. Three ligand solutions were prepared by dissolving $\mathrm{H}_{2} \mathrm{~L}$ ( $21 \mathrm{mg}, 0.10 \mathrm{mmol}$ ), $\mathrm{H}_{2}{ }^{\mathrm{Br}} \mathrm{L}^{\prime}(9 \mathrm{mg}, 0.030 \mathrm{mmol})$, or $\mathrm{H}_{2}{ }^{\mathrm{Cl}} \mathrm{L}^{\prime}(15 \mathrm{mg}, 0.072 \mathrm{mmol})$ in DMF (8 mL). To these solutions, aqueous $\mathrm{NaOH}$ solutions $(0.02 \mathrm{~mol} / \mathrm{L})$ were added and $\mathrm{pH}$ values were measured using a Fisherbrand Accumet $\mathrm{AB} 15 \mathrm{pH}$ meter. Values of $\mathrm{p} K_{\mathrm{a} 1}$ were calculated based on the $\mathrm{pH}$ values prior to the addition of $\mathrm{NaOH}$ (see main text for details). For each ligand, up to 2 equivalents of 
$\mathrm{NaOH}$ was added. A blank titration curve was prepared by gradually adding up to $0.5 \mathrm{~mL}$ of $\mathrm{NaOH}$ aqueous solution in DMF (3 mL).

$\mathbf{N}_{2}$ Adsorption and Desorption. DMF-solvated samples were soaked in $10 \mathrm{~mL}$ of $\mathrm{CH}_{2} \mathrm{Cl}_{2}$ for at least $48 \mathrm{~h}$, during which the solvent was decanted and replaced with fresh $\mathrm{CH}_{2} \mathrm{Cl}_{2}$ five times. The samples were pre-activated under vacuum for $3 \mathrm{~h}$, transferred to an MBraun Ar glovebox, and loaded into pre-weighed borosilicate measurement tubes capped with Micromeritics Transeals. The samples were then placed under vacuum at $80^{\circ} \mathrm{C}$ on a Micromeritics ASAP 2420 gas adsorption analyzer until the outgas rate was less than $2 \mu \mathrm{bar} / \mathrm{min}$, typically 24 to $48 \mathrm{~h}$. The evacuated sample tubes were then re-weighed to determine the mass of the activated samples and were transferred to the analysis ports of the instrument. $\mathrm{N}_{2}$ adsorption and desorption isotherms were measured at $77 \mathrm{~K}$ using a liquid $\mathrm{N}_{2}$ bath, and surface area were calculated using BrunauerEmmett-Teller (BET) model. 
Table S1 | Crystallographic data for MOFs 2-6.

\begin{tabular}{|c|c|c|c|c|c|}
\hline MOF $^{\mathrm{a}}$ & $\left(\mathrm{Et}_{4} \mathrm{~N}\right)_{2}\left[\mathrm{Zn}_{2} \mathrm{~L}_{1.3}{ }^{\mathrm{Br}} \mathrm{L}_{1.7}^{\prime}\right](\mathbf{2})$ & $\left(\mathrm{Et}_{4} \mathrm{~N}\right)_{2}\left[\mathrm{Zn}_{2} \mathrm{~L}_{1.1}{ }^{\mathrm{Cl}} \mathrm{L}_{1.9}^{\prime}\right](\mathbf{3})$ & $\left(\mathrm{Me}_{2} \mathrm{NH}_{2}\right)_{2}\left[\mathrm{Mn}_{2} \mathrm{~L}_{3}\right](4)$ & $\left(\mathrm{Et}_{4} \mathrm{~N}\right)_{2}\left[\mathrm{Mn}_{2} \mathrm{~L}_{1.8}{ }^{\mathrm{Br}} \mathrm{L}_{1.2}^{\prime}\right](\mathbf{5})$ & $\left(\mathrm{Et}_{4} \mathrm{~N}\right)_{2}\left[\mathrm{Mn}_{2} \mathrm{~L}_{1.5}{ }^{\mathrm{Cl}} \mathrm{L}_{1.5}^{\prime}\right](\mathbf{6})$ \\
\hline Empirical formula & $\mathrm{C}_{34} \mathrm{H}_{43.4} \mathrm{Br}_{3.4} \mathrm{Cl}_{2.6} \mathrm{~N}_{5.4} \mathrm{O}_{8.6} \mathrm{Zn}_{2}$ & $\mathrm{C}_{32} \mathrm{H}_{43.8} \mathrm{Cl}_{6} \mathrm{~N}_{5.8} \mathrm{O}_{8.2} \mathrm{Zn}_{2}$ & $\mathrm{C}_{22} \mathrm{H}_{16} \mathrm{Cl}_{6} \mathrm{Mn}_{2} \mathrm{~N}_{2} \mathrm{O}_{12}$ & $\mathrm{C}_{34} \mathrm{H}_{42.4} \mathrm{Br}_{2.4} \mathrm{Cl}_{3.6} \mathrm{Mn}_{2} \mathrm{~N}_{4.4} \mathrm{O}_{9.6}$ & $\mathrm{C}_{34} \mathrm{H}_{43} \mathrm{Cl}_{6} \mathrm{Mn}_{2} \mathrm{~N}_{5} \mathrm{O}_{9}$ \\
\hline Formula weight & 1159.99 & 1008.43 & 822.98 & 1095.65 & 988.35 \\
\hline Temperature/K & 99.99 & 99.99 & 250.01 & 100.02 & 99.99 \\
\hline Crystal system & trigonal & trigonal & trigonal & trigonal & trigonal \\
\hline Space group & $P-31 m$ & $P-31 m$ & $P-31 m$ & $P-31 m$ & $P-31 m$ \\
\hline$a, b / \AA$ & $13.9416(16)$ & $13.9533(10)$ & $14.017(4)$ & $14.1160(5)$ & $14.1380(11)$ \\
\hline$c / \AA$ & $10.2616(12)$ & $10.1333(11)$ & $8.970(2)$ & $9.9697(10)$ & $10.1420(12)$ \\
\hline Volume $/ \AA^{3}$ & $1727.3(4)$ & $1708.6(3)$ & $1526.3(9)$ & $1720.4(2)$ & $1755.6(3)$ \\
\hline$\rho_{\text {calc }} \mathrm{g} / \mathrm{cm}^{3}$ & 1.115 & 0.980 & 0.895 & 1.057 & 0.935 \\
\hline$\mu / \mathrm{mm}^{-1}$ & 2.795 & 3.313 & 0.708 & 6.205 & 5.316 \\
\hline $\mathrm{F}(000)$ & 577.0 & 516.0 & 410.0 & 549.0 & 506.0 \\
\hline Crystal size $/ \mathrm{mm}^{3}$ & $0.091 \times 0.085 \times 0.011$ & $0.196 \times 0.136 \times 0.07$ & $0.26 \times 0.192 \times 0.162$ & $0.6 \times 0.5 \times 0.1$ & $0.346 \times 0.307 \times 0.122$ \\
\hline Radiation & $\operatorname{MoK} \alpha(\lambda=0.71073)$ & $\operatorname{CuK} \alpha(\lambda=1.54178)$ & $\operatorname{MoK} \alpha(\lambda=0.71073)$ & $\mathrm{CuK} \alpha(\lambda=1.54178)$ & $\mathrm{CuK} \alpha(\lambda=1.54178)$ \\
\hline $2 \theta$ range & 5.21 to 41.606 & 11.396 to 94.358 & 5.648 to 41.578 & 11.452 to 100.974 & 11.328 to 94.22 \\
\hline Index ranges & $\begin{array}{l}-13 \leq h \leq 13 \\
-13 \leq k \leq 13 \\
-10 \leq l \leq 10\end{array}$ & $\begin{array}{l}-13 \leq h \leq 13 \\
-12 \leq k \leq 11 \\
-9 \leq l \leq 9\end{array}$ & $\begin{array}{l}-13 \leq h \leq 13 \\
-13 \leq k \leq 14 \\
-8 \leq l \leq 8\end{array}$ & $\begin{array}{l}-14 \leq h \leq 8 \\
-10 \leq k \leq 13 \\
-9 \leq l \leq 9\end{array}$ & $\begin{array}{l}-9 \leq h \leq 12 \\
-13 \leq k \leq 9 \\
-9 \leq l \leq 9\end{array}$ \\
\hline $\begin{array}{l}\text { Total/independent } \\
\text { reflections }\end{array}$ & $10580 / 668$ & $7875 / 570$ & $10280 / 572$ & $2931 / 658$ & $7061 / 589$ \\
\hline $\begin{array}{l}\text { Data/restraints/paramete } \\
\text { rs }\end{array}$ & $668 / 28 / 71$ & $570 / 36 / 71$ & $572 / 9 / 48$ & $658 / 40 / 75$ & $589 / 12 / 38$ \\
\hline Goodness-of-fit & 1.065 & 1.399 & 2.113 & 1.283 & 1.841 \\
\hline $\begin{array}{l}\text { Final R indexes }[I>=2 \sigma \\
\text { (I)] }\end{array}$ & $\mathrm{R}_{1}=0.0632^{\mathrm{b}} ; \mathrm{wR} \mathrm{R}_{2}=0.1768^{\mathrm{c}}$ & $\mathrm{R}_{1}=0.1125 ; \mathrm{w} \mathrm{R}_{2}=0.3075$ & $\mathrm{R}_{1}=0.1492 ; \mathrm{wR}_{2}=0.376$ & $\mathrm{R}_{1}=0.0962 ; \mathrm{w} \mathrm{R}_{2}=0.2713$ & $\mathrm{R}_{1}=0.1680 ; w \mathrm{R}_{2}=0.4226$ \\
\hline $\begin{array}{l}\text { Final } R \text { indexes [all } \\
\text { data] }\end{array}$ & $\mathrm{R}_{1}=0.0917 ; \mathrm{w} \mathrm{R}_{2}=0.1966$ & $\mathrm{R}_{1}=0.1373 ; \mathrm{wR}_{2}=0.3324$ & $\mathrm{R}_{1}=0.1590 ; \mathrm{wR}_{2}=0.438$ & $3 \mathrm{R}_{1}=0.1197 ; \mathrm{wR}_{2}=0.3105$ & $\mathrm{R}_{1}=0.1924 ; w \mathrm{R}_{2}=0.4455$ \\
\hline $\begin{array}{l}\text { Largest diff. peak/hole / } \\
\mathrm{e} \AA^{-3}\end{array}$ & $0.65 /-0.41$ & $1.19 /-0.42$ & $1.68 /-0.53$ & $0.76 /-0.63$ & $2.10 /-0.55$ \\
\hline
\end{tabular}

${ }^{a}$ The discrepancy of the formulae is due to the SC-XRD experimental procedure that involves in soaking crystals in DMF, as detailed above

${ }^{\mathrm{b}} R_{1}=\Sigma|| F_{0}|-| F_{\mathrm{C}}|| / \Sigma\left|F_{0}\right|$

${ }^{c} w R_{2}=\left[\Sigma \mathrm{w}\left(F_{0}^{2}-F_{\mathrm{C}}^{2}\right)^{2} / \Sigma \mathrm{w}\left(F_{\mathrm{o}}^{2}\right)^{2}\right]^{1 / 2}$ 
Table S2 | EDX spectra for $\left(\mathrm{Et}_{4} \mathrm{~N}\right)_{2}\left[\mathrm{Mn}_{2} \mathrm{~L}_{1.8}{ }^{\mathrm{Br}} \mathrm{L}_{1.2}^{\prime}\right] \cdot 0.65 \mathrm{DMF}(\mathbf{5}$, batch 1)

\begin{tabular}{|c|c|c|c|c|c|}
\hline Spectrum & $\mathrm{Br} \%^{\mathrm{a}}$ & $\mathrm{Cl} \%^{\mathrm{a}}$ & $\operatorname{Mn} \%^{a}$ & $\mathrm{Br}:(\mathrm{Br}+\mathrm{Cl})$ & Electron Image \\
\hline 1 & 25.0 & 51.8 & 23.2 & $0.326: 1$ & \\
\hline 2 & 28.5 & 49.3 & 22.2 & $0.366: 1$ & \\
\hline 3 & 27.9 & 50.2 & 21.9 & $0.357: 1$ & \\
\hline 4 & 29.4 & 47.5 & 23.1 & $0.383: 1$ & \\
\hline 5 & 28.7 & 48.4 & 22.9 & $0.372: 1$ & \\
\hline 6 & 29.4 & 48.1 & 22.5 & $0.380: 1$ & \\
\hline 7 & 28.2 & 49.2 & 22.6 & $0.364: 1$ & \\
\hline 8 & 27.3 & 50.0 & 22.7 & $0.353: 1$ & \\
\hline 9 & 31.4 & 47.4 & 21.2 & $0.398: 1$ & \\
\hline 10 & 32.4 & 46.0 & 21.5 & $0.413: 1$ & \\
\hline 11 & 33.8 & 44.3 & 21.8 & $0.433: 1$ & \\
\hline 12 & 32.6 & 45.1 & 22.3 & $0.420: 1$ & \\
\hline 13 & 31.1 & 47.5 & 21.4 & $0.396: 1$ & \\
\hline 14 & 37.0 & 39.6 & 23.4 & $0.483: 1$ & \\
\hline 15 & 31.7 & 46.3 & 22.0 & $0.406: 1$ & \\
\hline 16 & 33.5 & 44.2 & 22.3 & $0.431: 1$ & \\
\hline 17 & 30.7 & 44.1 & 25.2 & $0.410: 1$ & \\
\hline
\end{tabular}




\begin{tabular}{ccccc}
18 & 30.8 & 44.8 & 24.3 & $0.407: 1$ \\
19 & 28.4 & 47.0 & 24.5 & $0.377: 1$ \\
20 & 31.7 & 43.3 & 25.1 & $0.423: 1$ \\
21 & 28.9 & 46.3 & 24.8 & $0.385: 1$ \\
22 & 31.9 & 42.8 & 25.3 & $0.427: 1$ \\
23 & 29.4 & 46.3 & 24.3 & $0.389: 1$ \\
\hline 24 & 29.3 & 46.1 & 24.6 & $0.389: 1$ \\
\hline Average & 30.4 & 46.5 & 23.1 & $0.395: 1$ \\
\hline STD & 2.72 & 1.32 & 2.52 & $0.033: 1$ \\
\hline
\end{tabular}

${ }^{\text {a }}$ Mole percentage, $\mathrm{Cl}+\mathrm{Mn}+\mathrm{Co}=100 \%$, same below. 
Table S3 | EDX spectra for $\left(\mathrm{Et}_{4} \mathrm{~N}\right)_{2}\left[\mathrm{Mn}_{2} \mathrm{~L}_{1.8}{ }^{\mathrm{Br}} \mathrm{L}_{1.2}^{\prime}\right](\mathbf{5}$, batch 2)

\begin{tabular}{|c|c|c|c|c|c|}
\hline Spectrum & $\mathrm{Br} \%$ & $\mathrm{Cl} \%$ & Mn\% & $\mathrm{Br}:(\mathrm{Br}+\mathrm{Cl})$ & Electron Image \\
\hline 1 & 31.2 & 46.2 & 22.6 & $0.403: 1$ & \\
\hline 2 & 30.8 & 45.5 & 23.7 & $0.404: 1$ & \\
\hline 3 & 32.2 & 44.8 & 23.0 & $0.418: 1$ & \\
\hline 4 & 31.1 & 45.5 & 23.4 & $0.406: 1$ & \\
\hline 5 & 32.1 & 43.8 & 24.1 & $0.423: 1$ & \\
\hline 6 & 31.4 & 43.3 & 25.3 & $0.420: 1$ & \\
\hline 7 & 30.7 & 43.7 & 25.5 & $0.413: 1$ & \\
\hline 8 & 29.9 & 44.1 & 26.0 & $0.404: 1$ & \\
\hline 9 & 31.8 & 42.6 & 25.6 & $0.427: 1$ & \\
\hline 10 & 31.9 & 41.3 & 26.7 & $0.436: 1$ & \\
\hline 11 & 27.5 & 45.8 & 26.7 & $0.375: 1$ & \\
\hline 12 & 29.1 & 43.4 & 27.5 & $0.402: 1$ & \\
\hline 13 & 26.9 & 46.5 & 26.6 & $0.367: 1$ & \\
\hline 14 & 25.0 & 48.5 & 26.5 & $0.340: 1$ & \\
\hline 15 & 28.1 & 48.3 & 23.6 & $0.368: 1$ & \\
\hline 16 & 31.9 & 43.2 & 24.9 & $0.425: 1$ & \\
\hline 17 & 27.4 & 45.2 & 27.3 & $0.377: 1$ & \\
\hline
\end{tabular}




\begin{tabular}{cccccccc}
18 & 30.3 & 42.1 & 27.5 & $0.418: 1$ \\
19 & 29.1 & 43.3 & 27.3 & $0.404: 1$ \\
20 & 28.9 & 42.1 & 29.0 & $0.407: 1$ \\
21 & 29.5 & 44.0 & 26.5 & $0.401: 1$ \\
22 & 30.4 & 44.7 & 25.0 & $0.404: 1$ \\
23 & 28.4 & 44.9 & 26.7 & $0.387: 1$ \\
24 & 30.0 & 44.7 & 25.3 & $0.402: 1$ \\
\hline STD & 1.86 & 1.75 & 1.63 & $0.022: 1$ \\
\hline Average & 29.8 & 44.5 & 25.7 & $0.401: 1$
\end{tabular}


Table S4 | EDX spectra for $\left(\mathrm{Et}_{4} \mathrm{~N}\right)_{2}\left[\mathrm{Mn}_{2} \mathrm{~L}_{1.8}{ }^{\mathrm{Br}} \mathrm{L}_{1.2}^{\prime}\right] \cdot 0.65 \mathrm{DMF}(\mathbf{5}$, batch 3)

\begin{tabular}{|c|c|c|c|c|c|}
\hline Spectrum & $\mathrm{Br} \%$ & $\mathrm{Cl} \%$ & Mn\% & $\mathrm{Br}:(\mathrm{Br}+\mathrm{Cl})$ & Electron Image \\
\hline 1 & 24.6 & 44.6 & 30.8 & $0.356: 1$ & \\
\hline 2 & 26.0 & 44.2 & 30.0 & $0.370: 1$ & \\
\hline 3 & 26.4 & 43.1 & 30.4 & $0.380: 1$ & \\
\hline 4 & 21.2 & 45.9 & 32.9 & $0.316: 1$ & \\
\hline 5 & 33.6 & 41.4 & 25.0 & $0.448: 1$ & \\
\hline 6 & 33.6 & 42.6 & 23.8 & $0.441: 1$ & \\
\hline 7 & 30.4 & 40.4 & 29.1 & $0.429: 1$ & \\
\hline 8 & 28.6 & 40.7 & 30.6 & $0.413: 1$ & \\
\hline 9 & 32.3 & 39.2 & 28.5 & $0.451: 1$ & \\
\hline 10 & 34.7 & 38.6 & 26.7 & $0.473: 1$ & \\
\hline 11 & 31.4 & 42.4 & 26.2 & $0.425: 1$ & \\
\hline 12 & 32.6 & 40.3 & 27.1 & $0.448: 1$ & \\
\hline 13 & 26.3 & 44.7 & 28.9 & $0.370: 1$ & \\
\hline 14 & 25.7 & 45.9 & 28.4 & $0.358: 1$ & \\
\hline 15 & 24.4 & 46.5 & 29.1 & $0.344: 1$ & \\
\hline 16 & 22.6 & 46.2 & 31.2 & $0.328: 1$ & \\
\hline 17 & 30.3 & 41.3 & 28.4 & $0.423: 1$ & \\
\hline
\end{tabular}




\begin{tabular}{cccccc}
18 & 33.6 & 41.1 & 25.2 & $0.450: 1$ \\
19 & 34.0 & 40.8 & 25.2 & $0.455: 1$ \\
20 & 30.5 & 40.3 & 29.2 & $0.431: 1$ \\
\hline Average & 29.7 & 42.0 & 28.3 & $0.406: 1$ \\
STD & 4.18 & 2.48 & 2.40 & $0.048: 1$ \\
\hline
\end{tabular}


Table S5 | EDX spectra for $\left(\mathrm{Et}_{4} \mathrm{~N}\right)_{2}\left[\mathrm{Mn}_{2} \mathrm{~L}_{1.8}{ }^{\mathrm{Br}} \mathrm{L}_{1.2}^{\prime}\right] \cdot 0.65 \mathrm{DMF}(\mathbf{5}$, batch 4$)$

\begin{tabular}{|c|c|c|c|c|c|}
\hline Spectrum & $\mathrm{Br} \%$ & $\mathrm{Cl} \%$ & Mn\% & $\mathrm{Br}:(\mathrm{Br}+\mathrm{Cl})$ & Electron Image \\
\hline 1 & 20.9 & 39.1 & 39.9 & $0.348: 1$ & \\
\hline 2 & 29.1 & 43.0 & 27.8 & $0.404: 1$ & \\
\hline 3 & 28.6 & 42.9 & 28.6 & $0.400: 1$ & \\
\hline 4 & 30.8 & 44.1 & 25.2 & $0.411: 1$ & \\
\hline 5 & 30.6 & 41.9 & 27.4 & $0.408: 1$ & \\
\hline 6 & 28.4 & 41.2 & 30.4 & $0.408: 1$ & \\
\hline 7 & 25.9 & 40.7 & 33.3 & $0.389: 1$ & \\
\hline 8 & 25.5 & 41.5 & 33.0 & $0.380: 1$ & \\
\hline 9 & 28.5 & 43.0 & 28.5 & $0.398: 1$ & \\
\hline 10 & 25.8 & 41.9 & 32.3 & $0.381: 1$ & \\
\hline 11 & 31.0 & 44.2 & 24.8 & $0.412: 1$ & \\
\hline 12 & 30.6 & 45.1 & 24.3 & $0.404: 1$ & \\
\hline 13 & 34.6 & 40.4 & 25.0 & $0.462: 1$ & \\
\hline 14 & 30.9 & 41.5 & 27.6 & $0.427: 1$ & \\
\hline 15 & 29.3 & 44.0 & 26.7 & $0.400: 1$ & \\
\hline 16 & 29.0 & 43.8 & 27.2 & $0.398: 1$ & \\
\hline 17 & 30.1 & 44.6 & 25.3 & $0.403: 1$ & \\
\hline
\end{tabular}




\begin{tabular}{ccccccc}
18 & 27.8 & 45.0 & 27.2 & $0.382: 1$ \\
19 & 28.5 & 43.6 & 27.9 & $0.395: 1$ \\
20 & 29.1 & 43.6 & 27.2 & $0.400: 1$ \\
21 & 28.6 & 44.0 & 27.4 & $0.393: 1$ \\
22 & 30.1 & 44.1 & 25.7 & $0.406: 1$ \\
23 & 29.5 & 43.6 & 26.8 & $0.404: 1$ \\
24 & 28.9 & 44.7 & 26.4 & $0.393: 1$ \\
\hline 25 & 29.5 & 43.2 & 27.2 & $0.406: 1$ \\
\hline Average & 28.7 & 43.1 & 28.2 & $0.401: 1$ \\
\hline STD & 2.50 & 1.56 & 3.42 & $0.020: 1$ \\
\hline
\end{tabular}



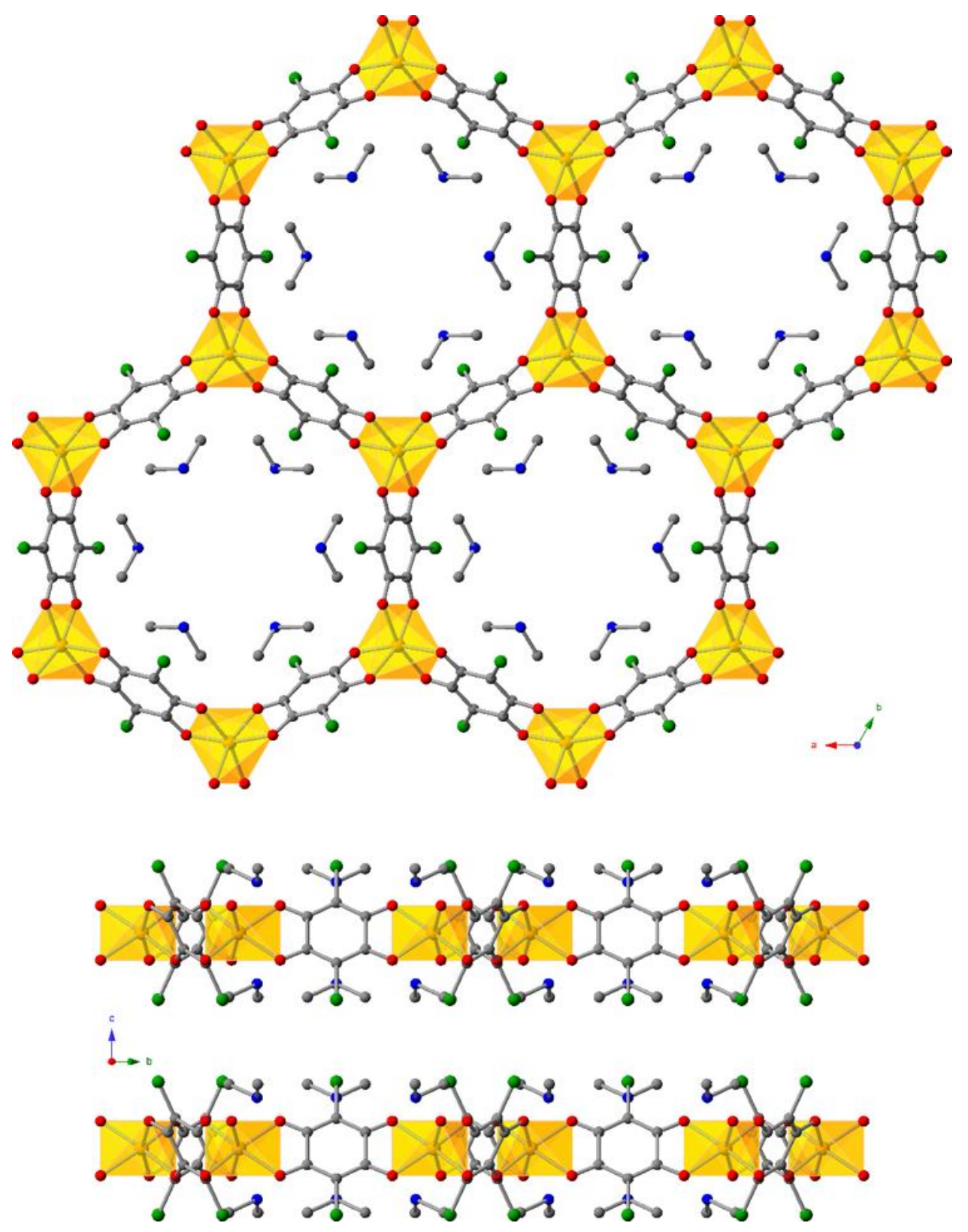

Figure S1. Single-crystal structure of $\left(\mathrm{Me}_{2} \mathrm{NH}_{2}\right)_{2}\left[\mathrm{Mn}_{2} \mathrm{~L}_{3}\right]$ (4) viewed along the crystallographic $c$ axis (upper) and $a$ axis (lower). Orange polyhedron represents $\mathrm{Mn}$ atom; green, red, blue and gray spheres represent $\mathrm{Cl}, \mathrm{O}, \mathrm{N}$, and $\mathrm{C}$ atoms. Solvent molecules and all hydrogen atoms are omitted for clarity. Every $\mathrm{Me}_{2} \mathrm{NH}_{2}{ }^{+}$counterion has an occupancy of $1 / 3$. 


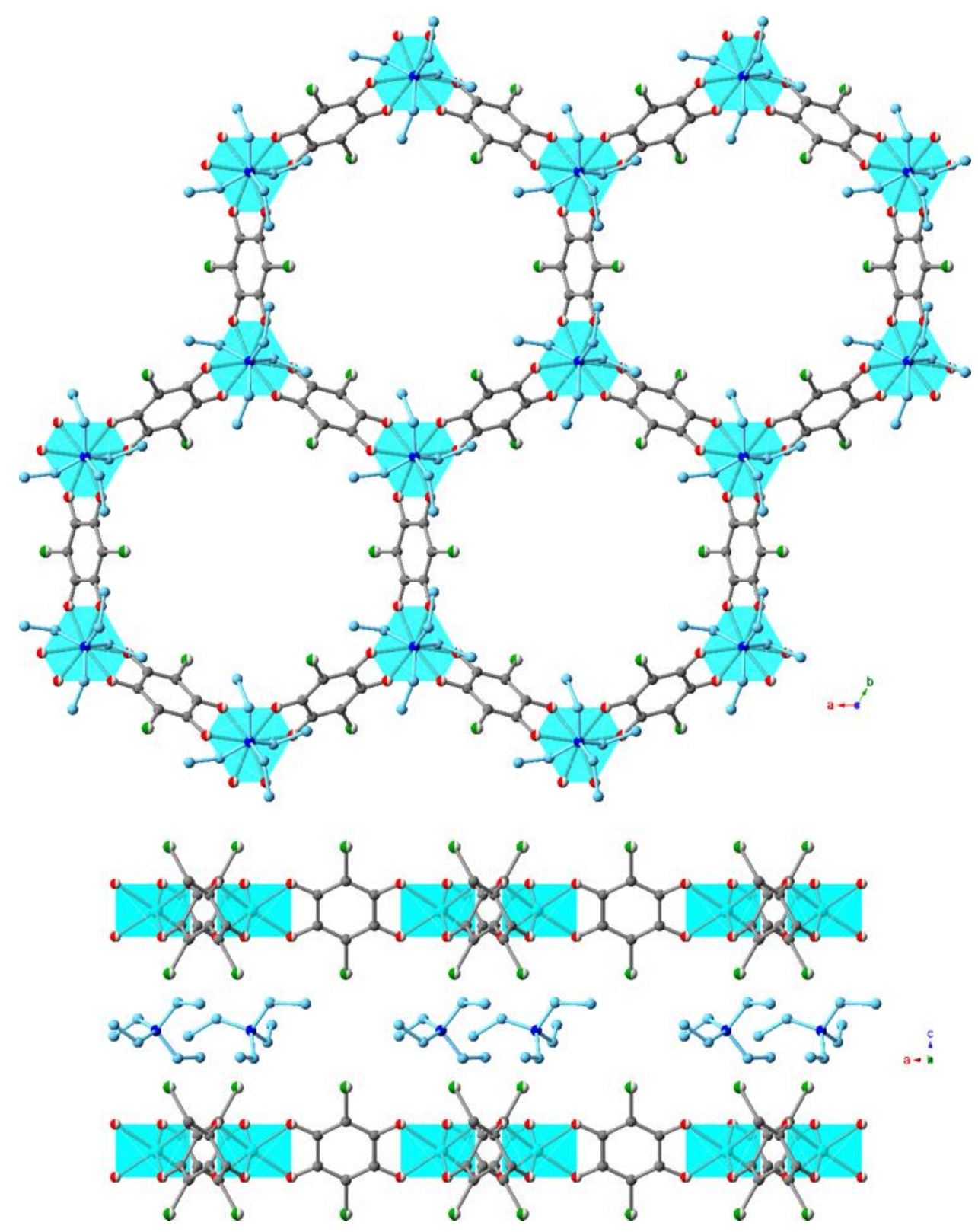

Figure S2. Single-crystal structure of $\left(\mathrm{Et}_{4} \mathrm{~N}\right)_{2}\left[\mathrm{Zn}_{2} \mathrm{~L}_{1.3}{ }^{\mathrm{Br}} \mathrm{L}_{1.7}{ }_{1.7}\right.$ (2) viewed along the crystallographic $c$ axis (upper) and $a$ axis (lower). Cyan polyhedra represent $\mathrm{Zn}$ atoms; blue spheres represent $\mathrm{N}$ atoms; light blue and gray spheres both represent $\mathrm{C}$ atoms; green-white and red-white dual colored spheres represent disordered $\mathrm{Cl} / \mathrm{Br}$ and $\mathrm{O} / \mathrm{N}$ atoms, respectively; $\mathrm{H}$ atoms are omitted for clarity. The $\mathrm{Et}_{4} \mathrm{~N}^{+}$counterion is disordered and only one orientation is shown. 


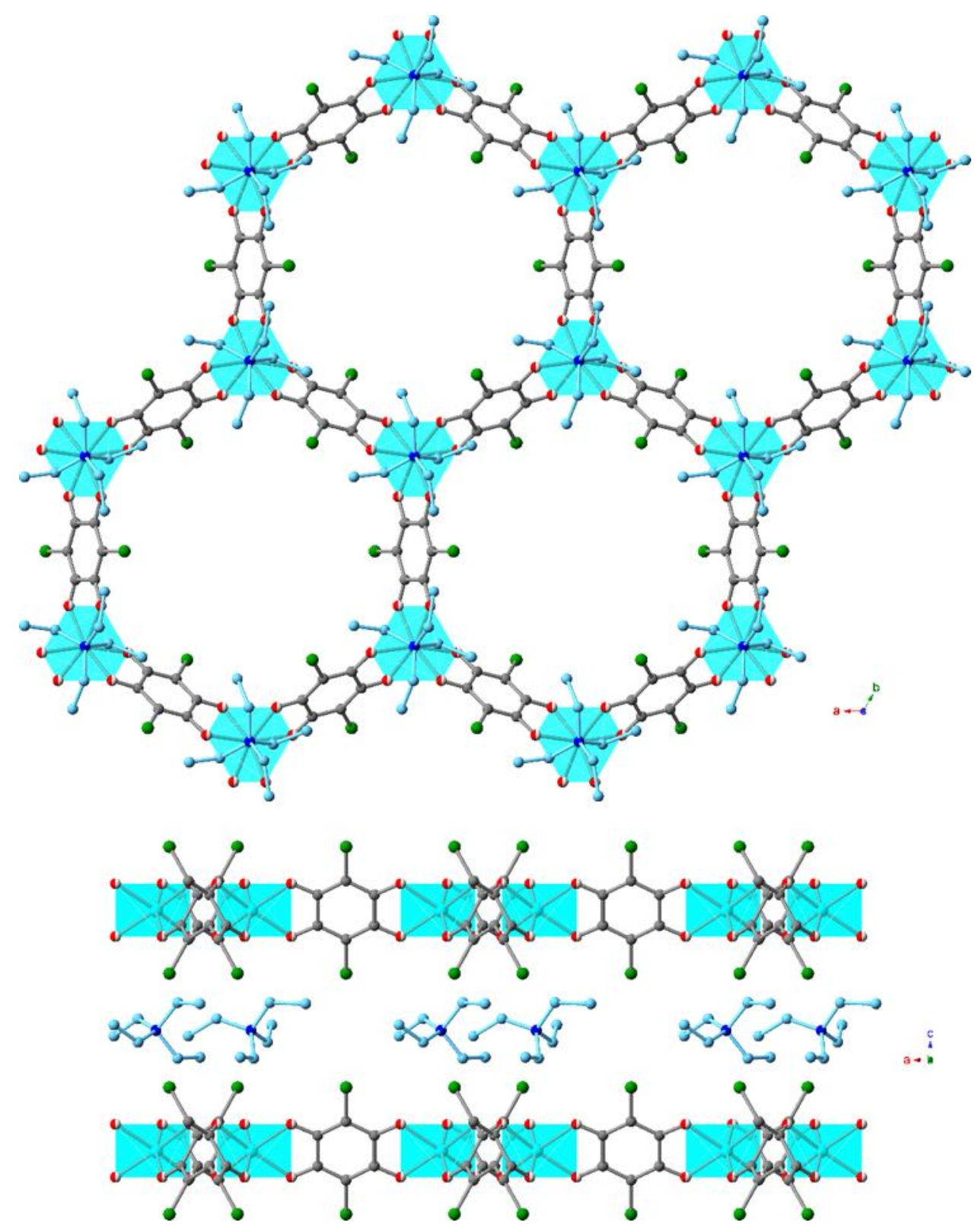

Figure S3. Single-crystal structure of $\left(\mathrm{Et}_{4} \mathrm{~N}\right)_{2}\left[\mathrm{Zn}_{2} \mathrm{~L}_{1.1}{ }^{\mathrm{Cl}} \mathrm{L}^{\prime}{ }_{1.9}\right]$ (3) viewed along the crystallographic $c$ axis (upper) and $a$ axis (lower). Cyan polyhedra represent $\mathrm{Zn}$ atom; blue and green spheres represent $\mathrm{N}$ and $\mathrm{Cl}$ atoms, respectively; light blue and gray spheres both represent $\mathrm{C}$ atoms; red-white dual colored sphere represent disordered $\mathrm{O} / \mathrm{N}$ atoms; $\mathrm{H}$ atoms are omitted for clarity. The $\mathrm{Et}_{4} \mathrm{~N}^{+}$counterion is disordered and only one orientation is shown. 


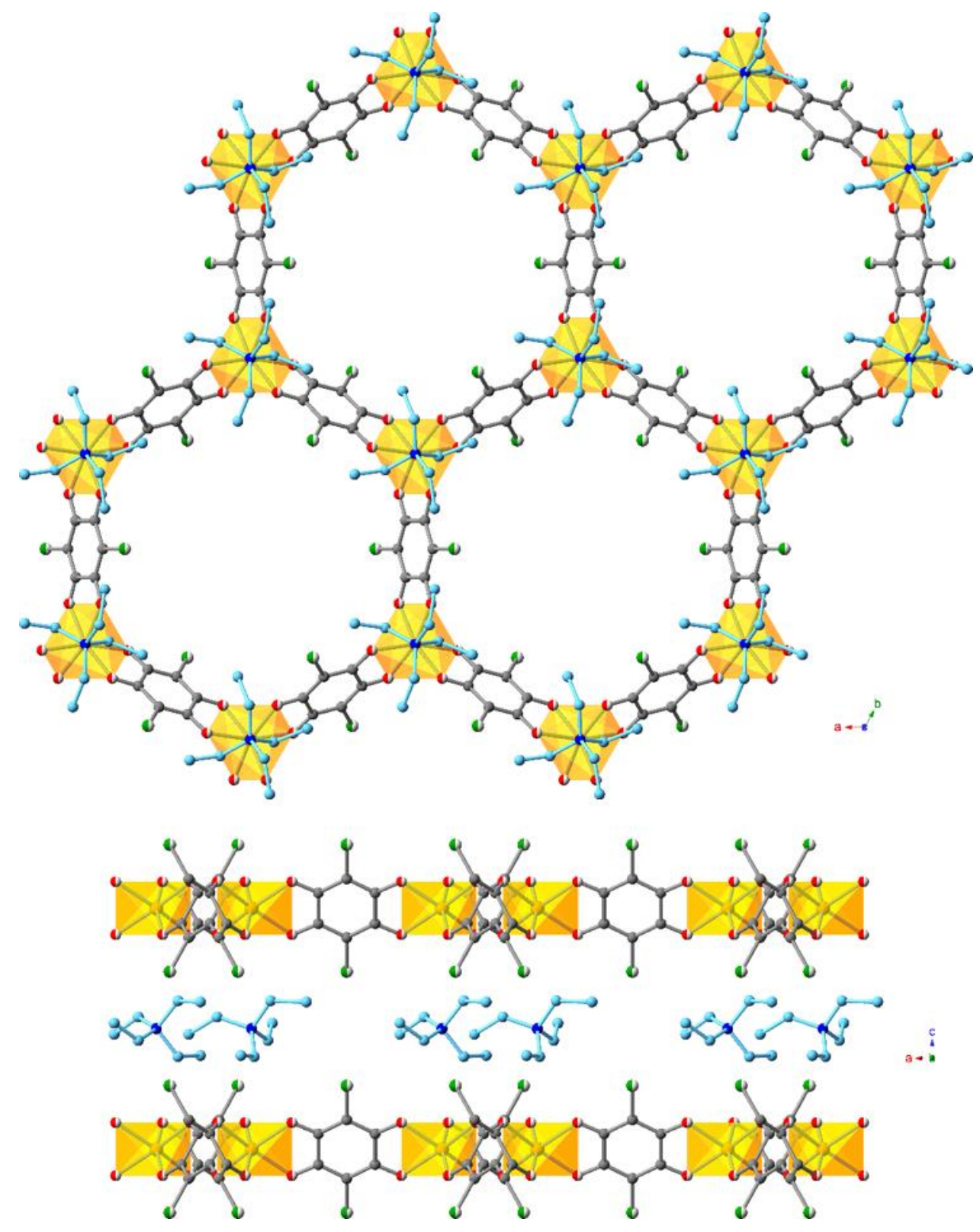

Figure S4. Single-crystal structure of $\left(\mathrm{Et}_{4} \mathrm{~N}\right)_{2}\left[\mathrm{Mn}_{2} \mathrm{~L}_{1.8}{ }^{\mathrm{Br}} \mathrm{L}_{1.2}^{\prime}\right]$ (5) viewed along the crystallographic $c$ axis (upper) and $a$ axis (lower). Orange polyhedra represents $\mathrm{Mn}$ atoms; blue spheres represents $\mathrm{N}$ atoms; light blue and gray spheres both represent $\mathrm{C}$ atoms; green-white and red-white dual colored spheres represent disordered $\mathrm{Cl} / \mathrm{Br}$ and $\mathrm{O} / \mathrm{N}$ atoms, respectively; $\mathrm{H}$ atoms are omitted for clarity. The $\mathrm{Et}_{4} \mathrm{~N}^{+}$counterion is disordered and only one orientation is shown. 


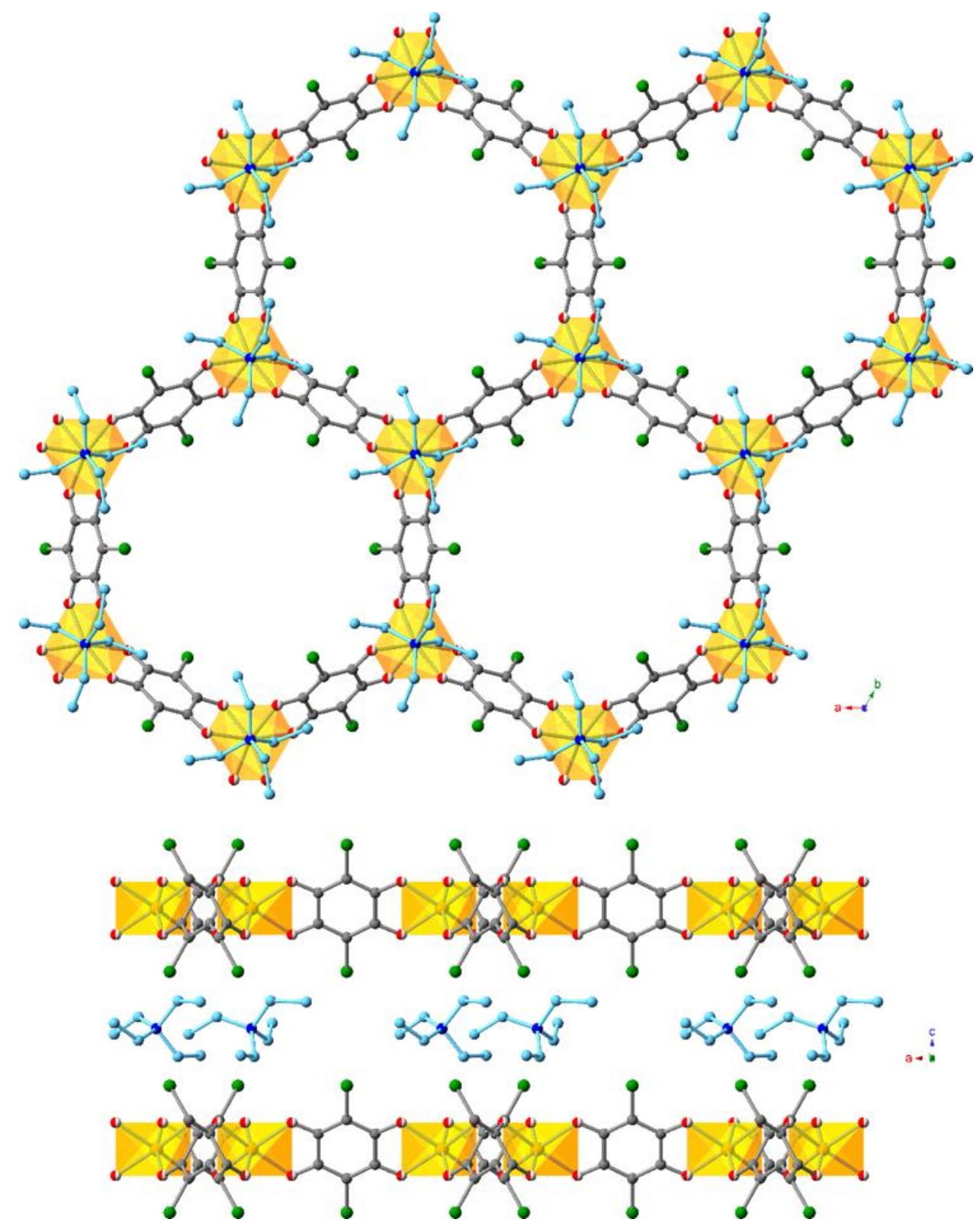

Figure S5. Single-crystal structure of $\left(\mathrm{Et}_{4} \mathrm{~N}\right)_{2}\left[\mathrm{Mn}_{2} \mathrm{~L}_{1.5}{ }^{\mathrm{Cl}} \mathrm{L}_{1.5}\right]$ (6) viewed along the crystallographic $c$ axis (upper) and $a$ axis (lower). Orange polyhedra represent $\mathrm{Mn}$ atoms; blue and green spheres represent $\mathrm{N}$ and $\mathrm{Cl}$ atoms, respectively; light blue and gray spheres both represent $\mathrm{C}$ atoms; red-white dual colored sphere represent disordered $\mathrm{O} / \mathrm{N}$ atoms; $\mathrm{H}$ atoms are omitted for clarity. The $\mathrm{Et}_{4} \mathrm{~N}^{+}$counterion is disordered and only one orientation is shown. 


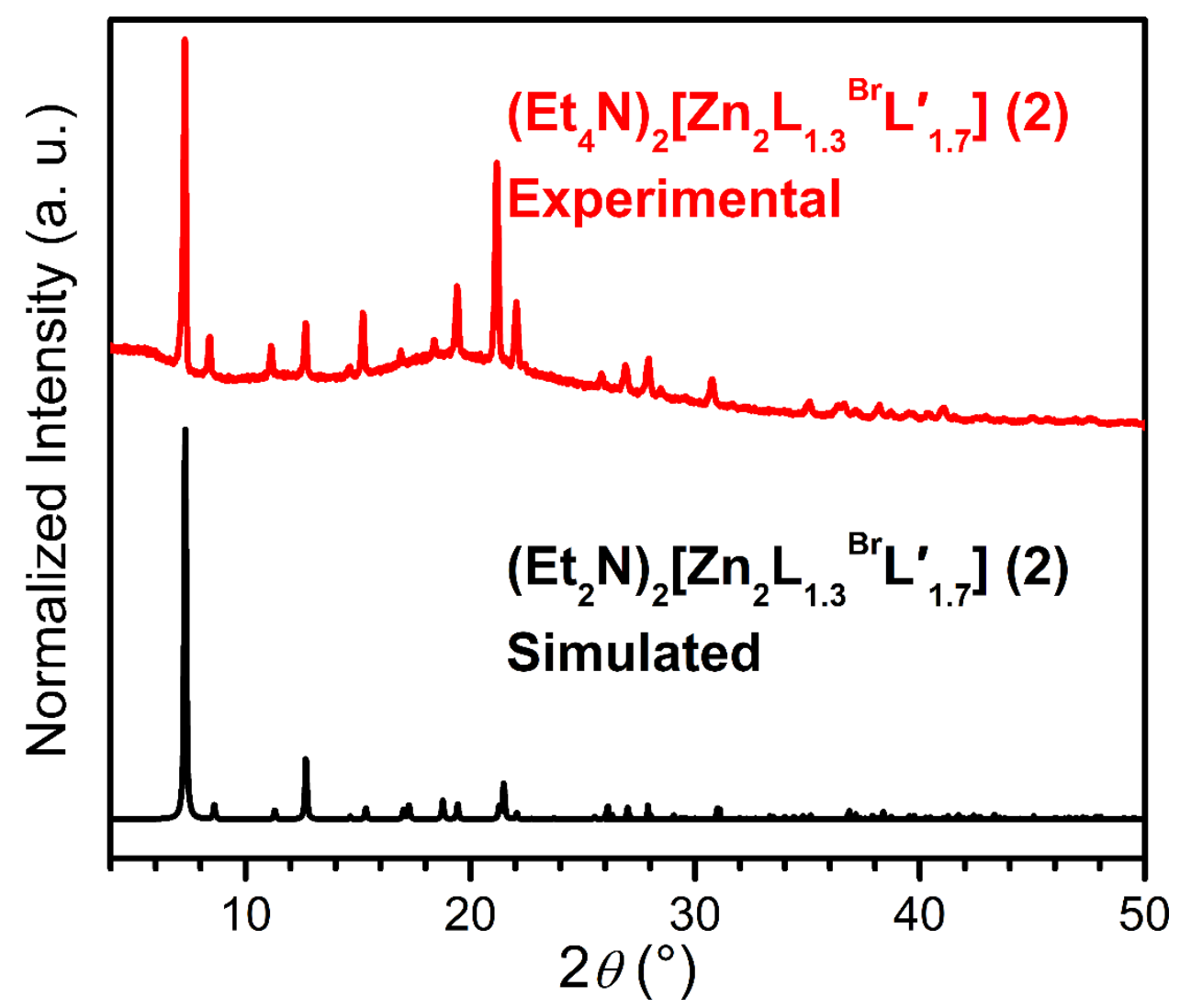

Figure S6. Experimental and simulated PXRD patterns for 2. 


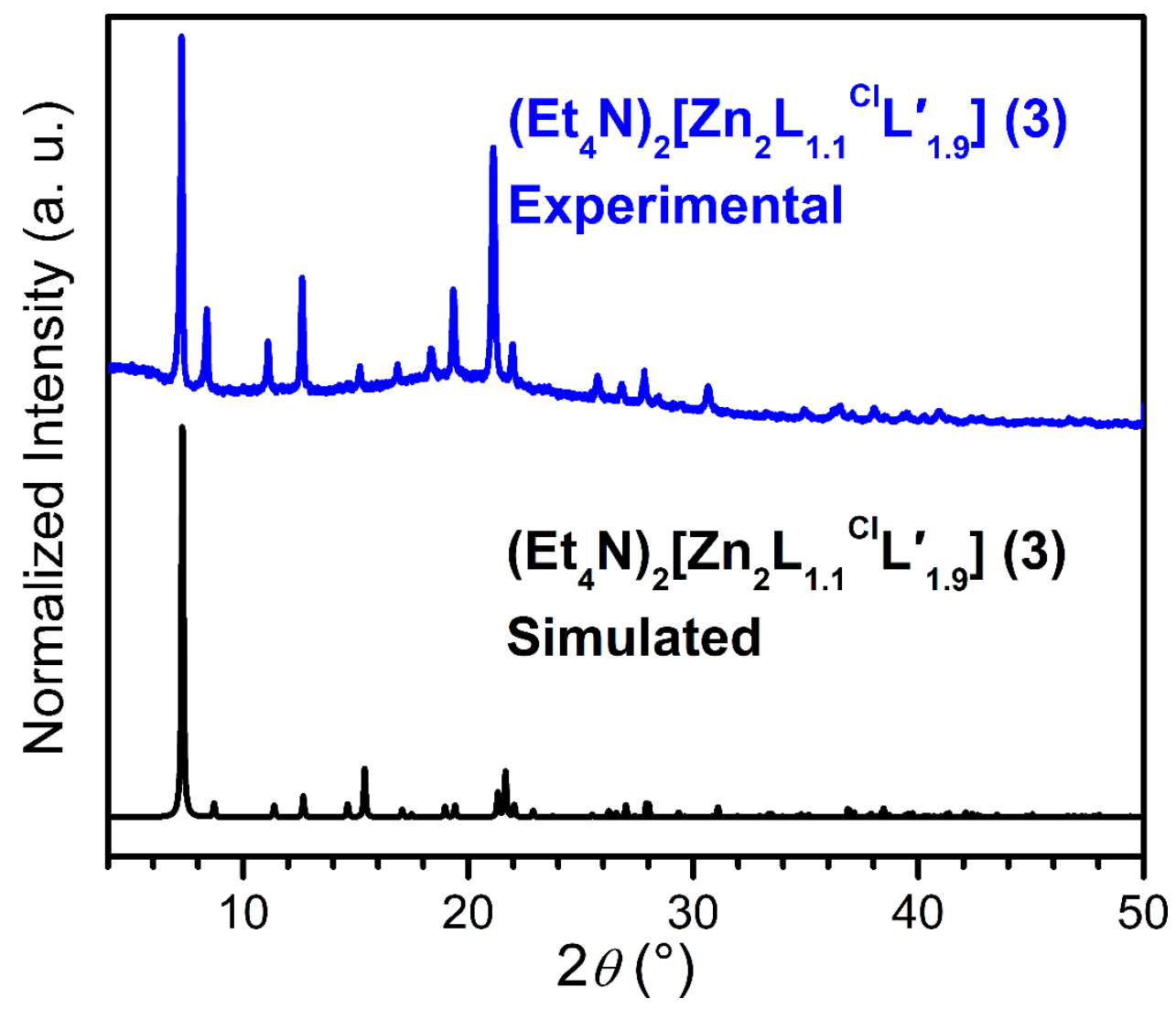

Figure S7. Experimental and simulated PXRD patterns for 3. 


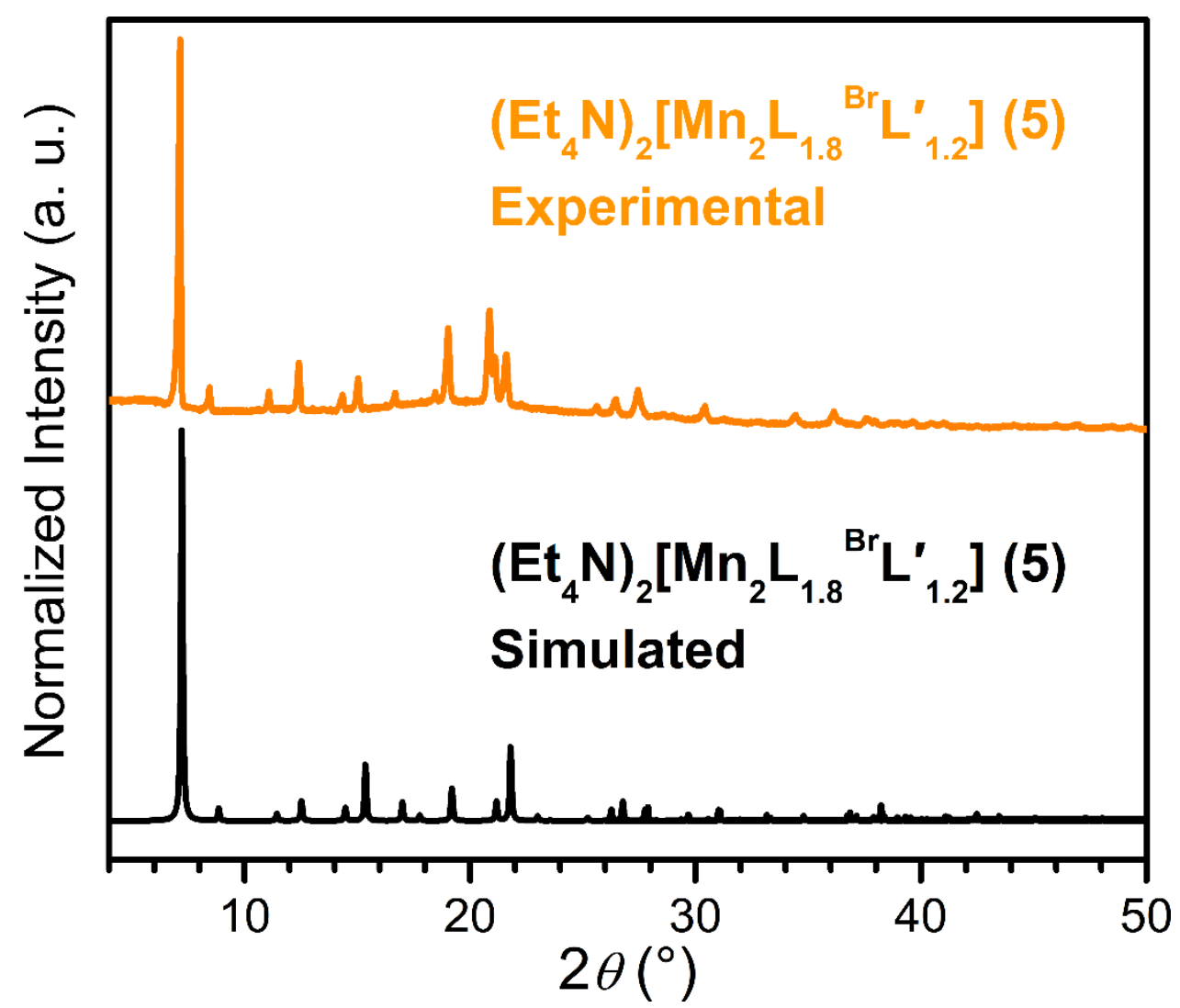

Figure S8. Experimental and simulated PXRD patterns for 5. 


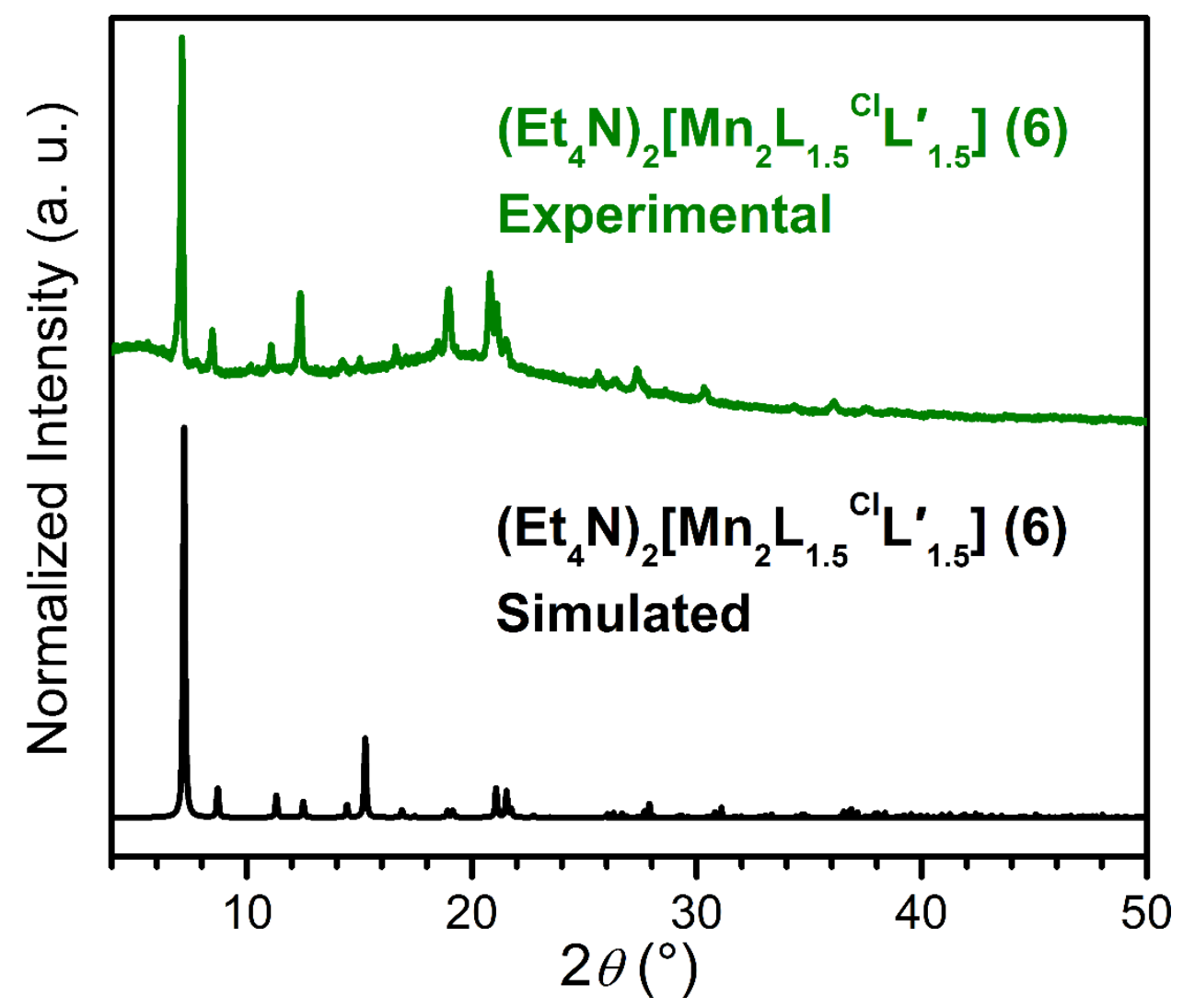

Figure S9. Experimental and simulated PXRD patterns for 6. 


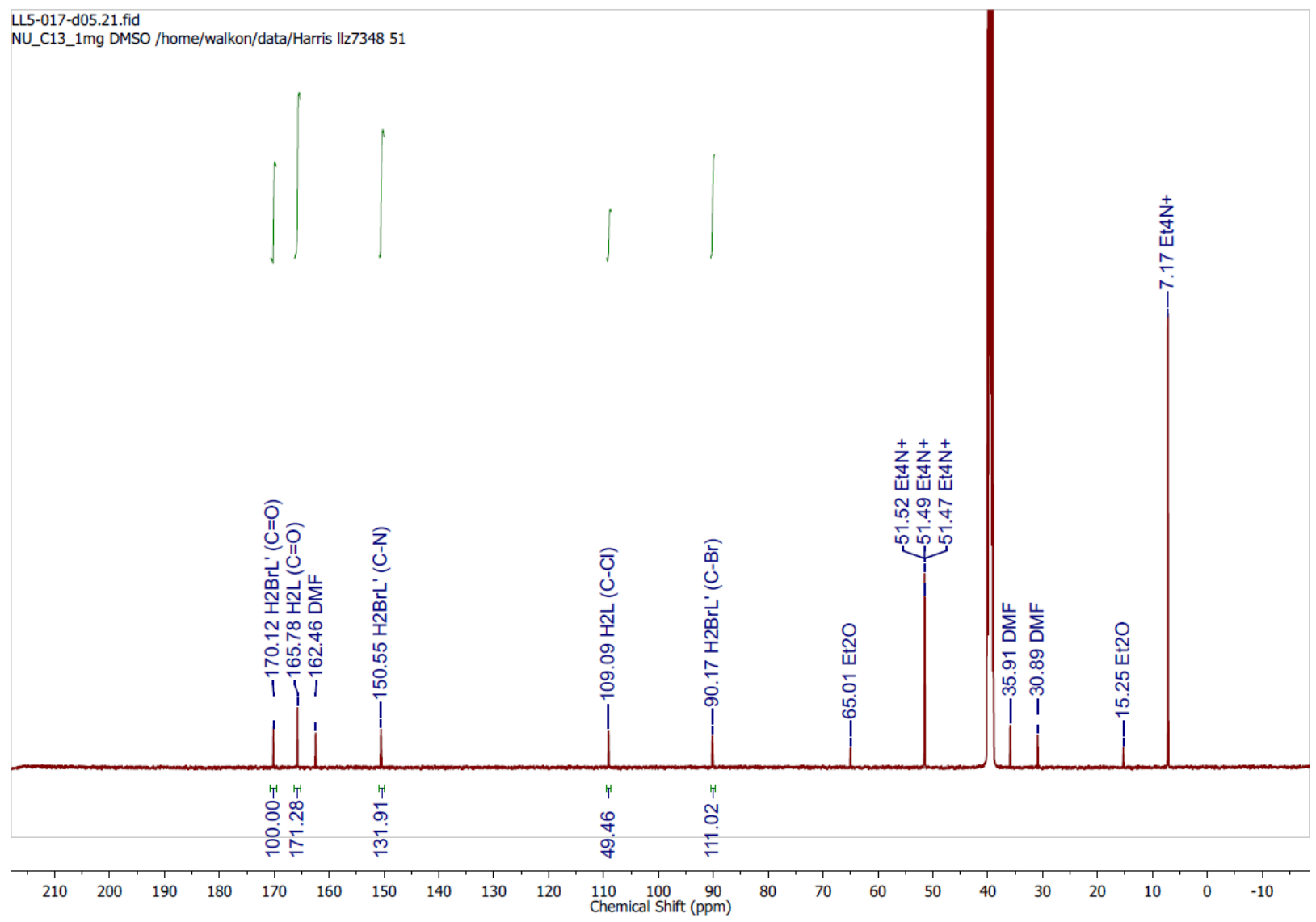

Figure S10. ${ }^{13} \mathrm{C}$ NMR spectrum for 2 . 


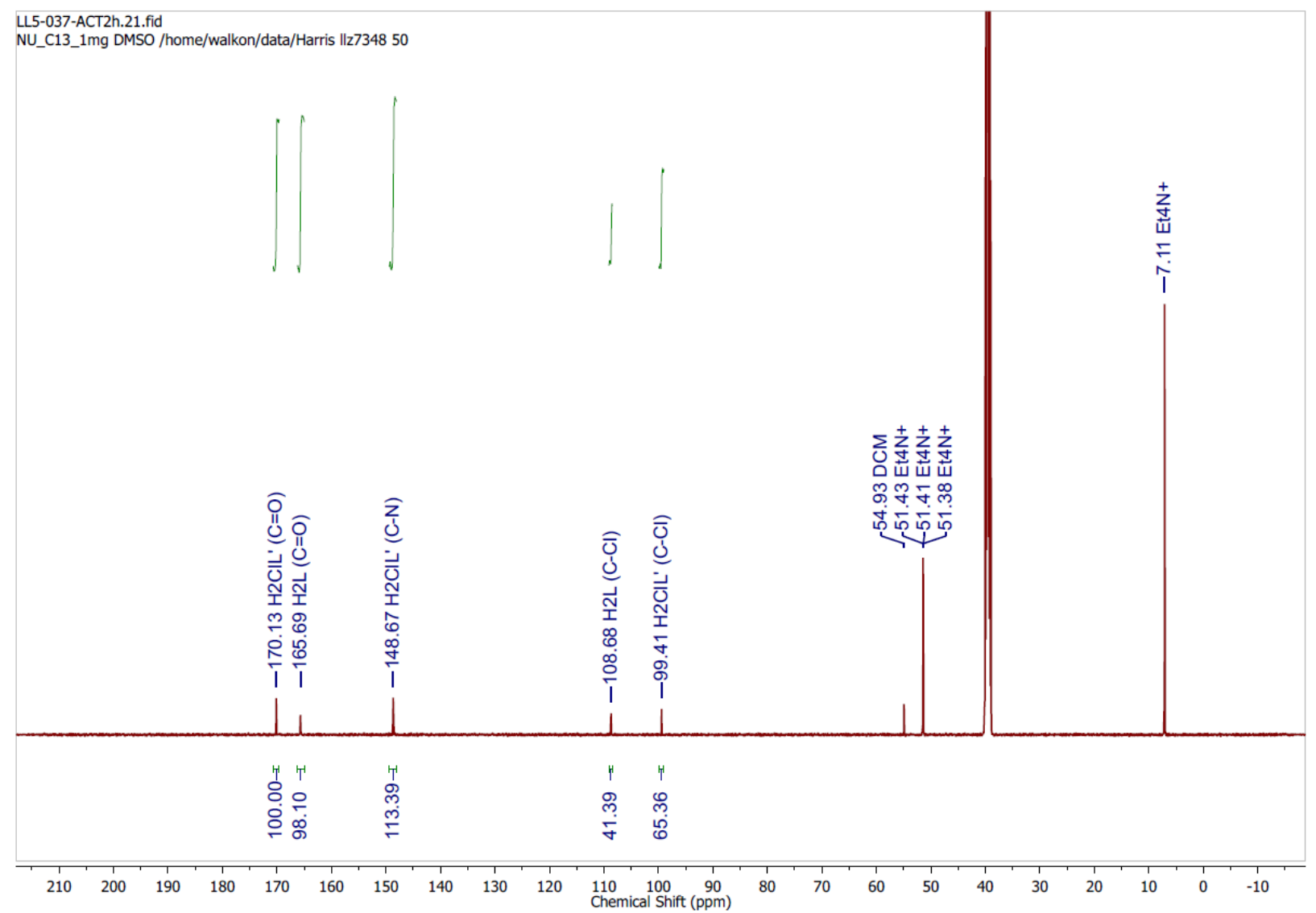

Figure S11. ${ }^{13} \mathrm{C}$ NMR spectrum for 3 . 


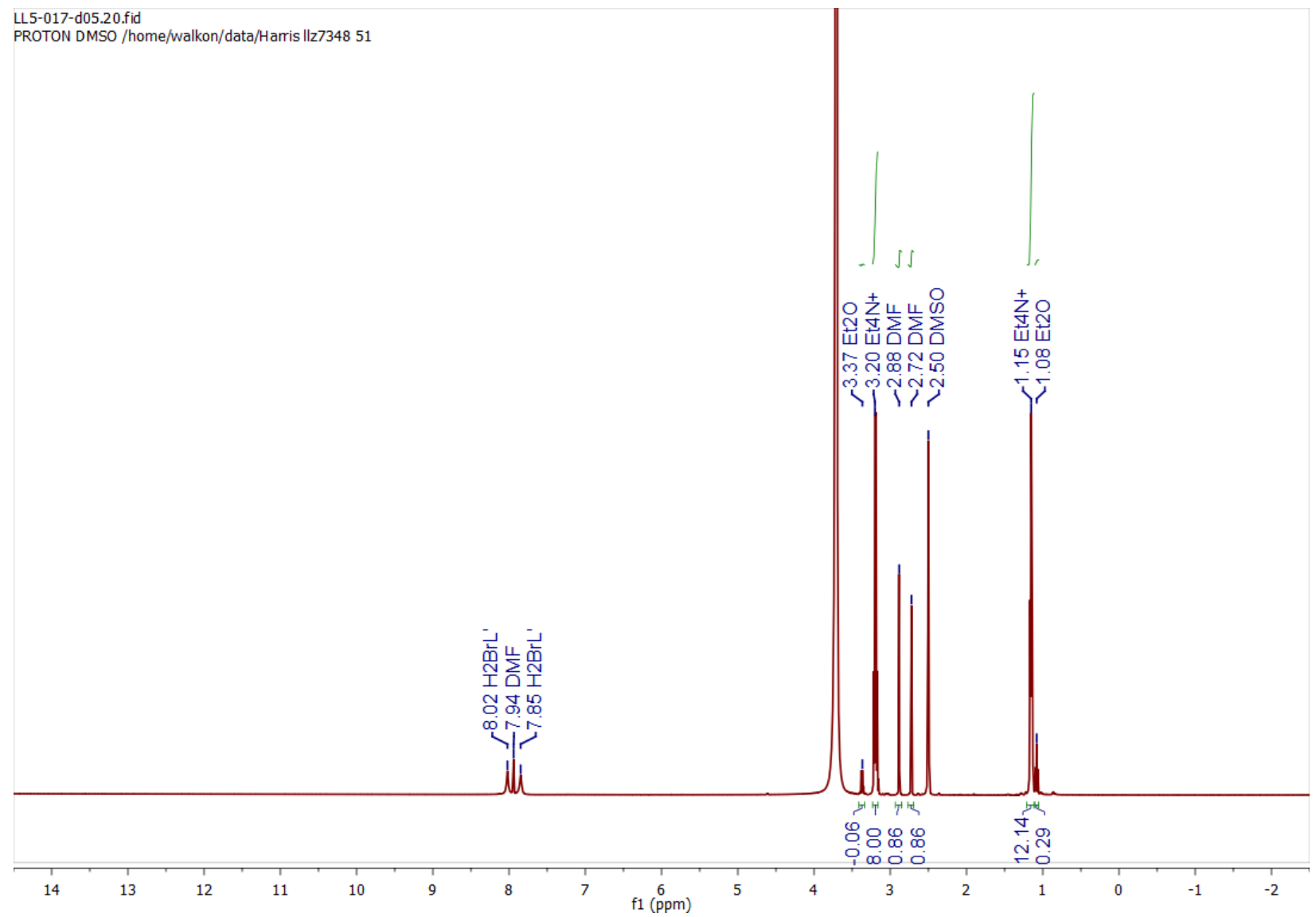

Figure S12. ${ }^{1} \mathrm{H}$ NMR spectrum for 2 . 


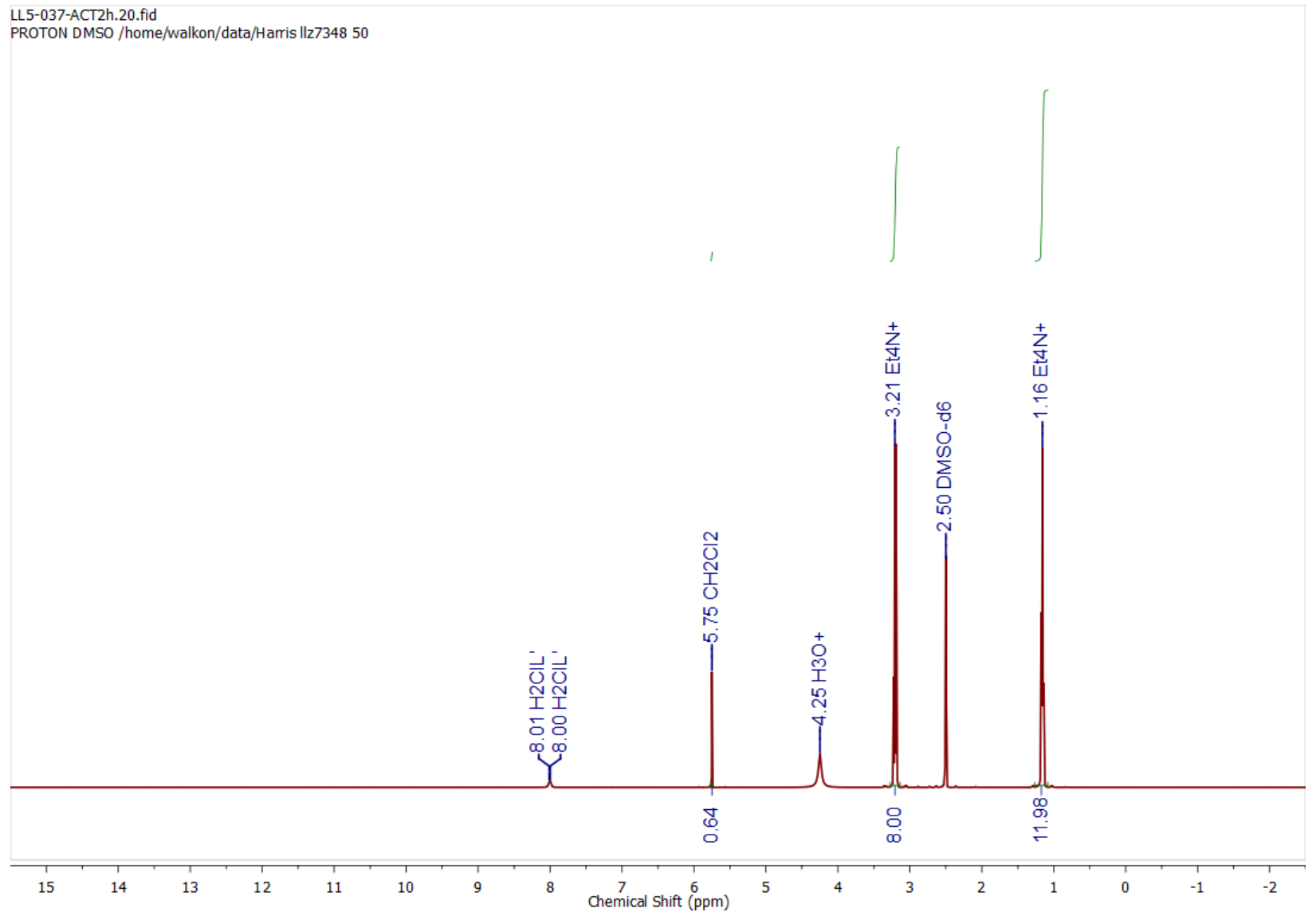

Figure S13. ${ }^{1} \mathrm{H}$ NMR spectrum for 3 . 


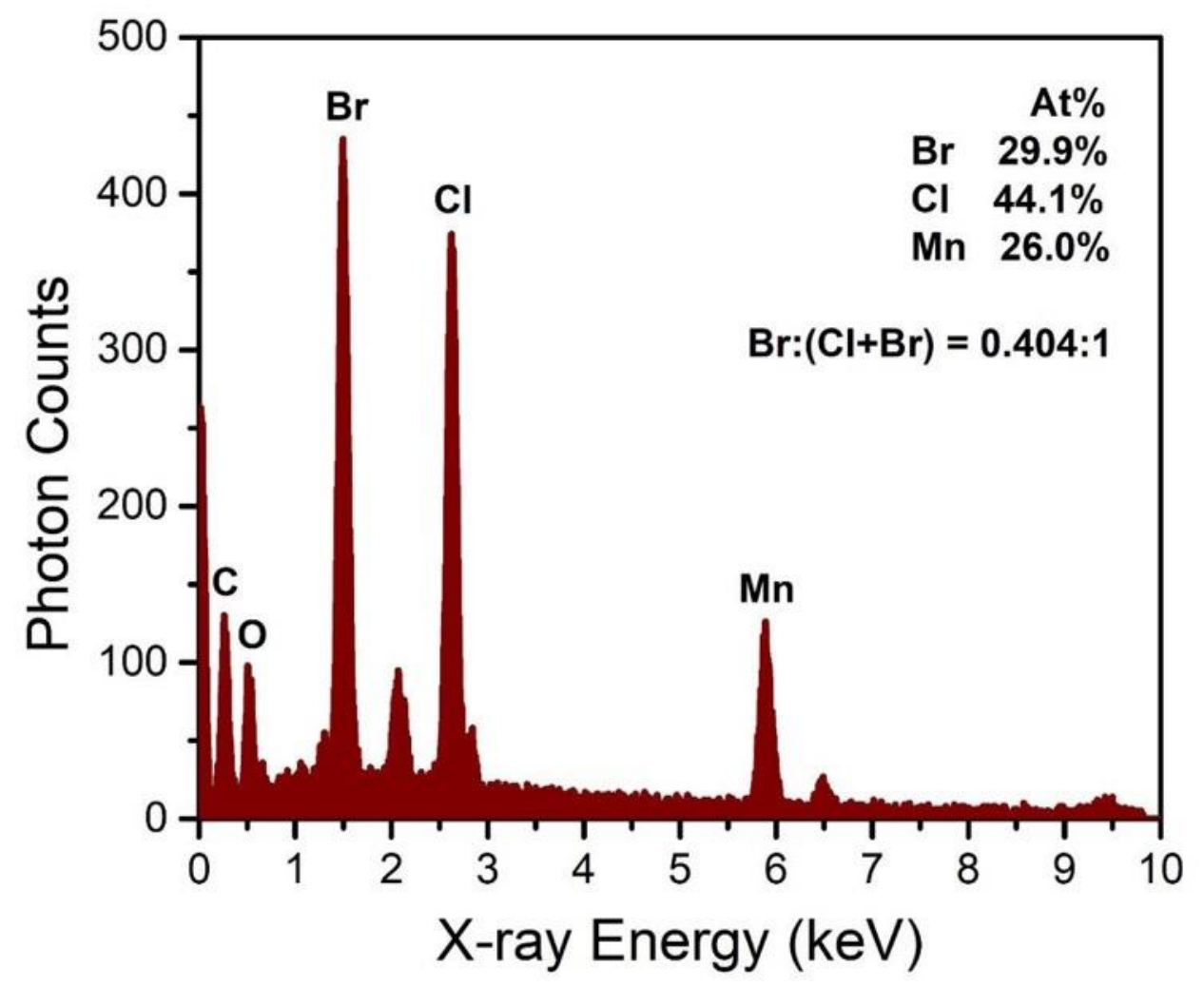

Figure S14. A representative EDX spectrum for 5, showing a 40\% linker exchange. 


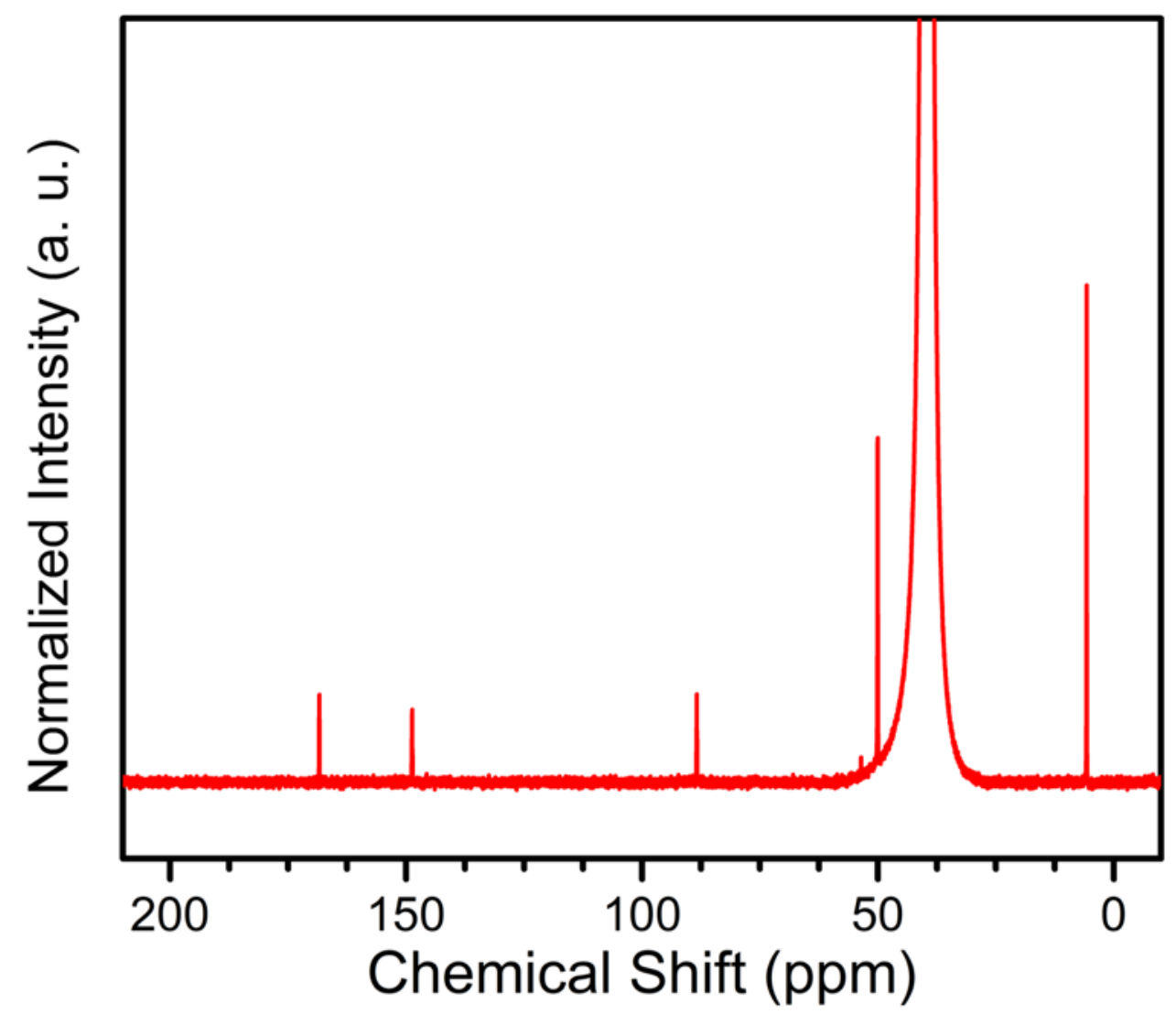

Figure S15. ${ }^{13} \mathrm{C}$ NMR spectrum for further activated sample of $\mathbf{5}$, showing the absence of DMF. This sample was used for combustion elemental analysis. 


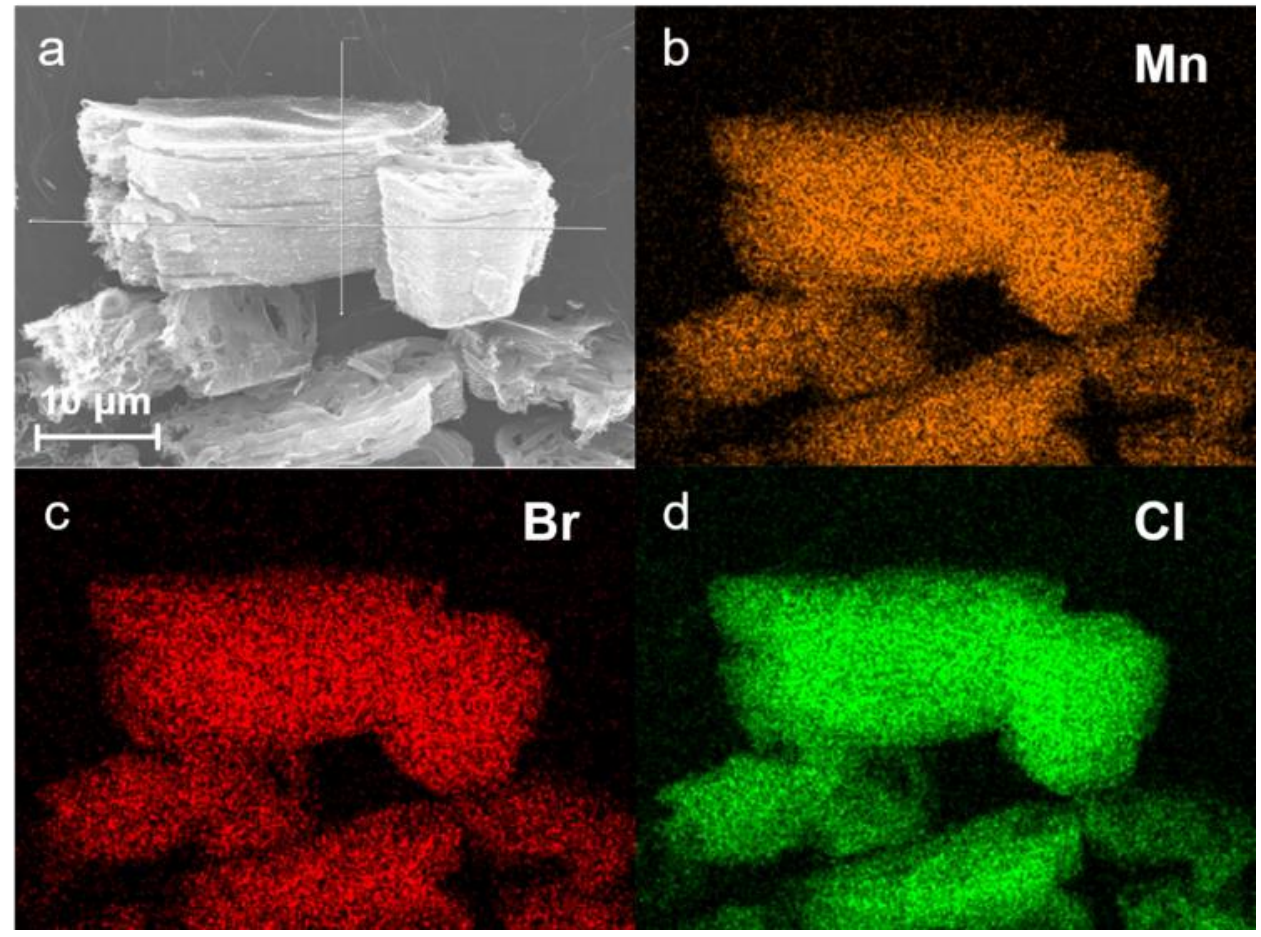

Figure S16. (a) SEM image of 5 (batch 1). (b)(c)(d) EDX mapping images with $\mathrm{Mn}, \mathrm{Br}$ and $\mathrm{Cl}$ elements. 


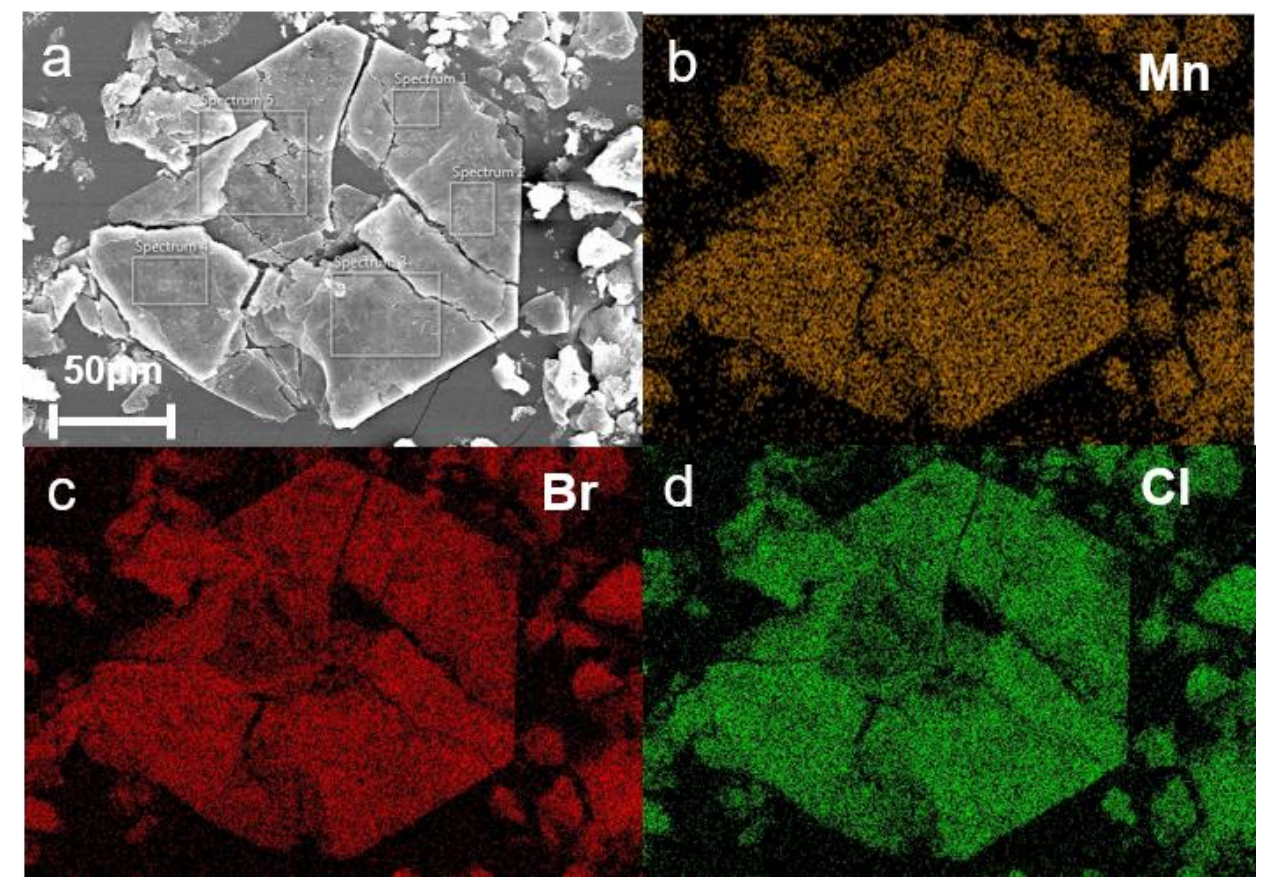

Figure S17. (a) SEM image of 5 (batch 2). (b)(c)(d) EDX mapping images with $\mathrm{Mn}, \mathrm{Br}$ and $\mathrm{Cl}$ elements. 


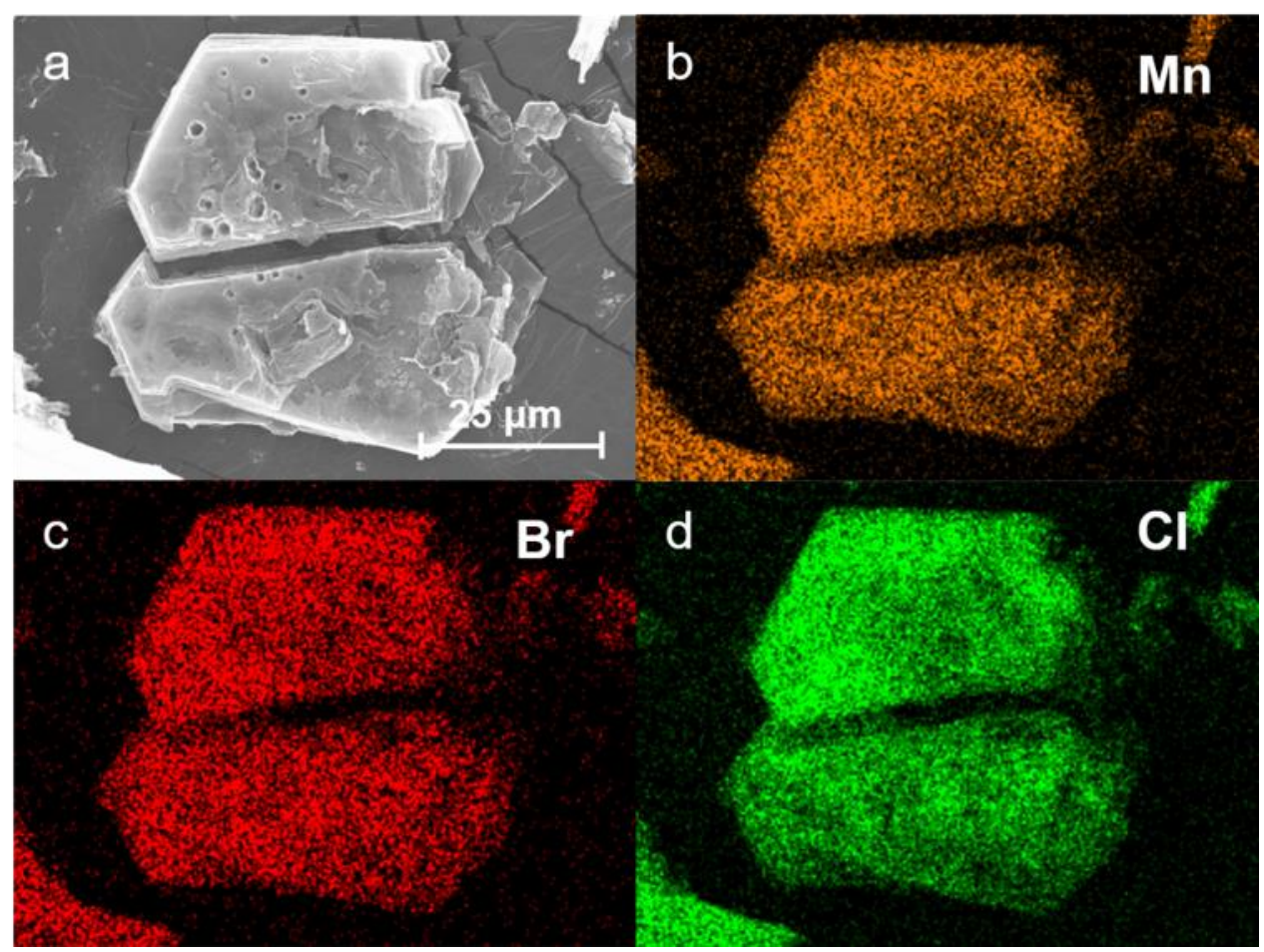

Figure S18. (a) SEM image of 5 (batch 3). (b)(c)(d) EDX mapping images with $\mathrm{Mn}, \mathrm{Br}$ and $\mathrm{Cl}$ elements. 


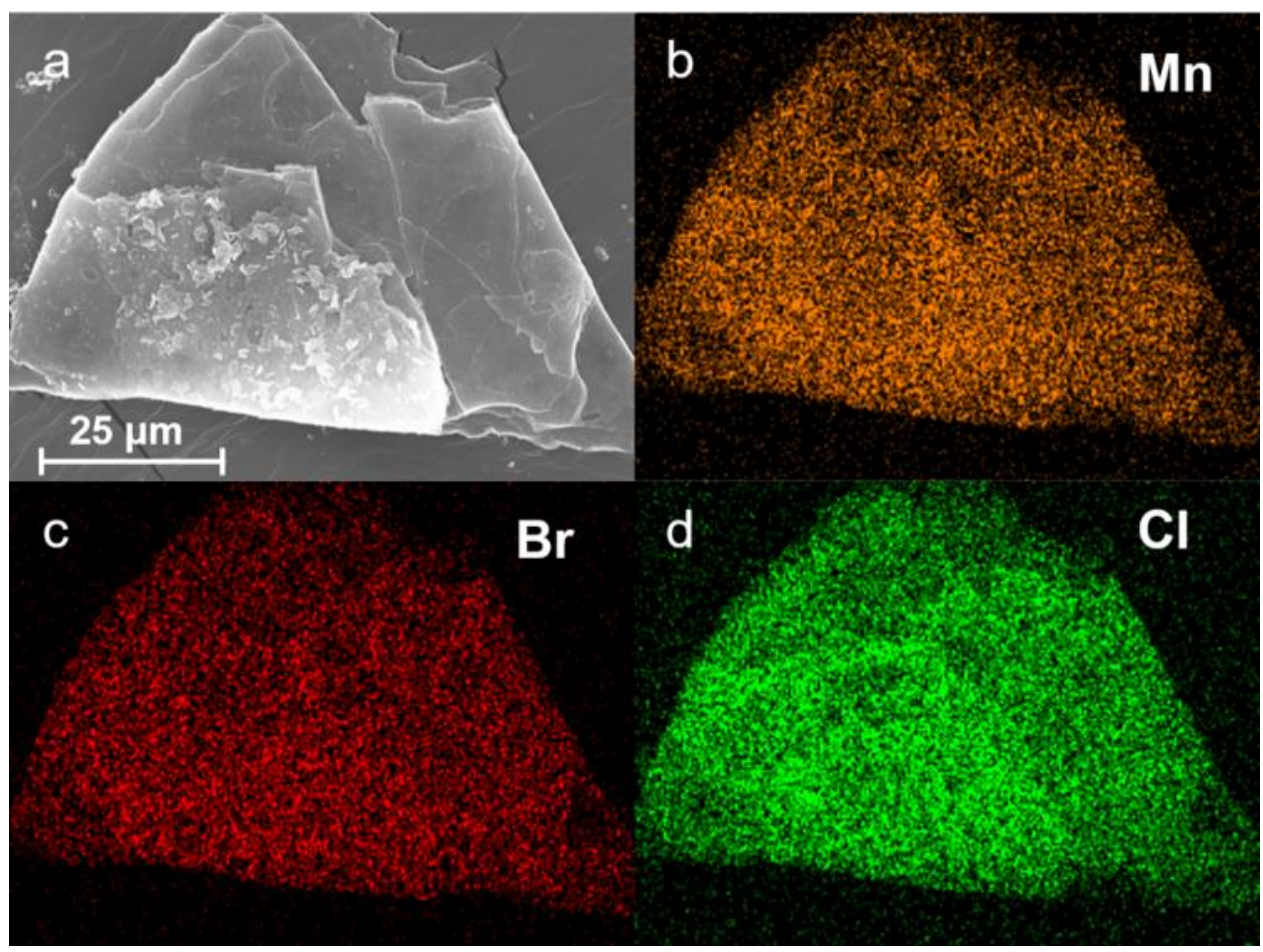

Figure S19. (a) SEM image of 5 (batch 4). (b)(c)(d) EDX mapping images with $\mathrm{Mn}, \mathrm{Br}$ and $\mathrm{Cl}$ elements. 


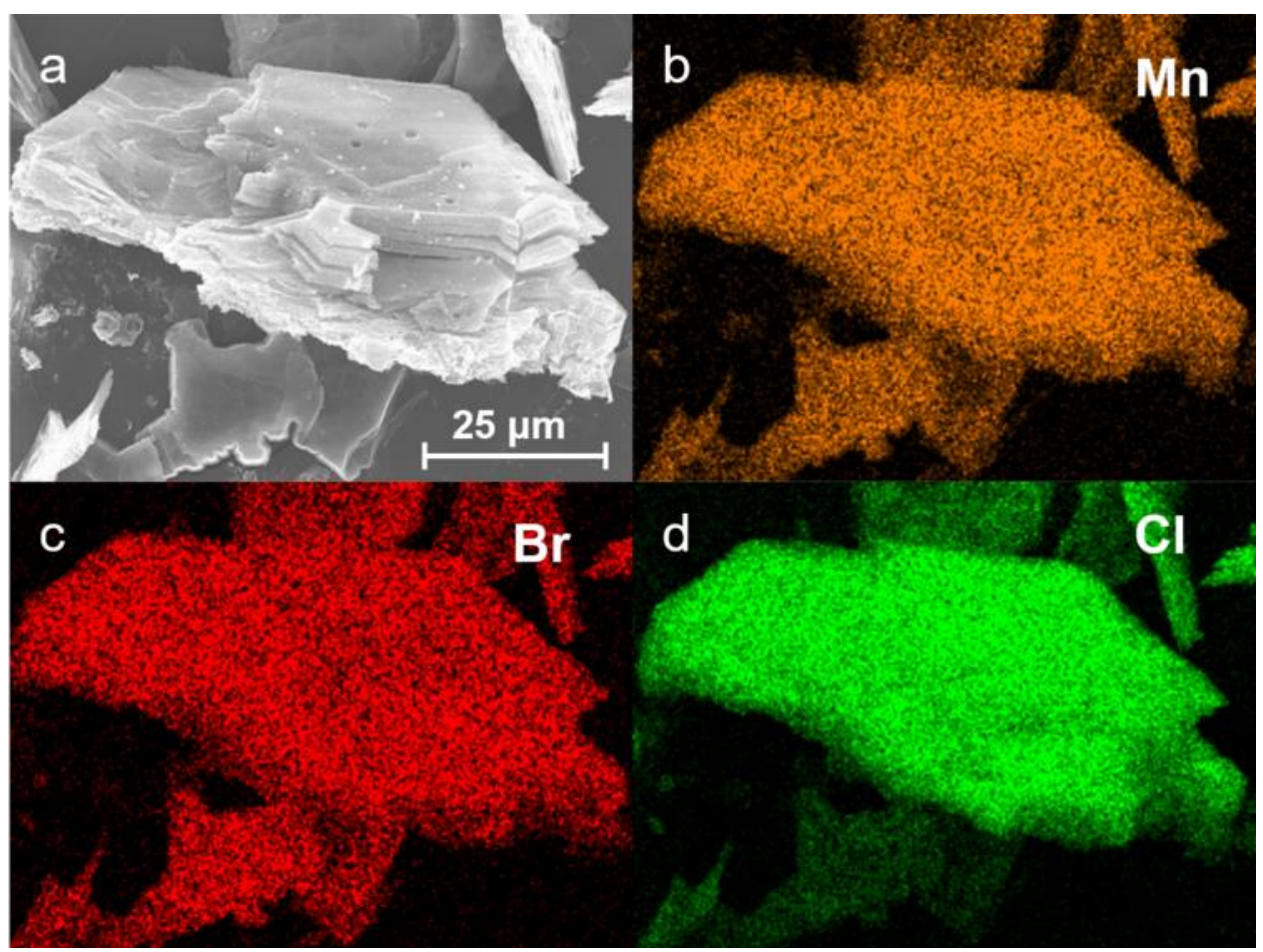

Figure S20. (a) SEM image of 5 (batch 5). (b)(c)(d) EDX mapping images with $\mathrm{Mn}, \mathrm{Br}$ and $\mathrm{Cl}$ elements. 


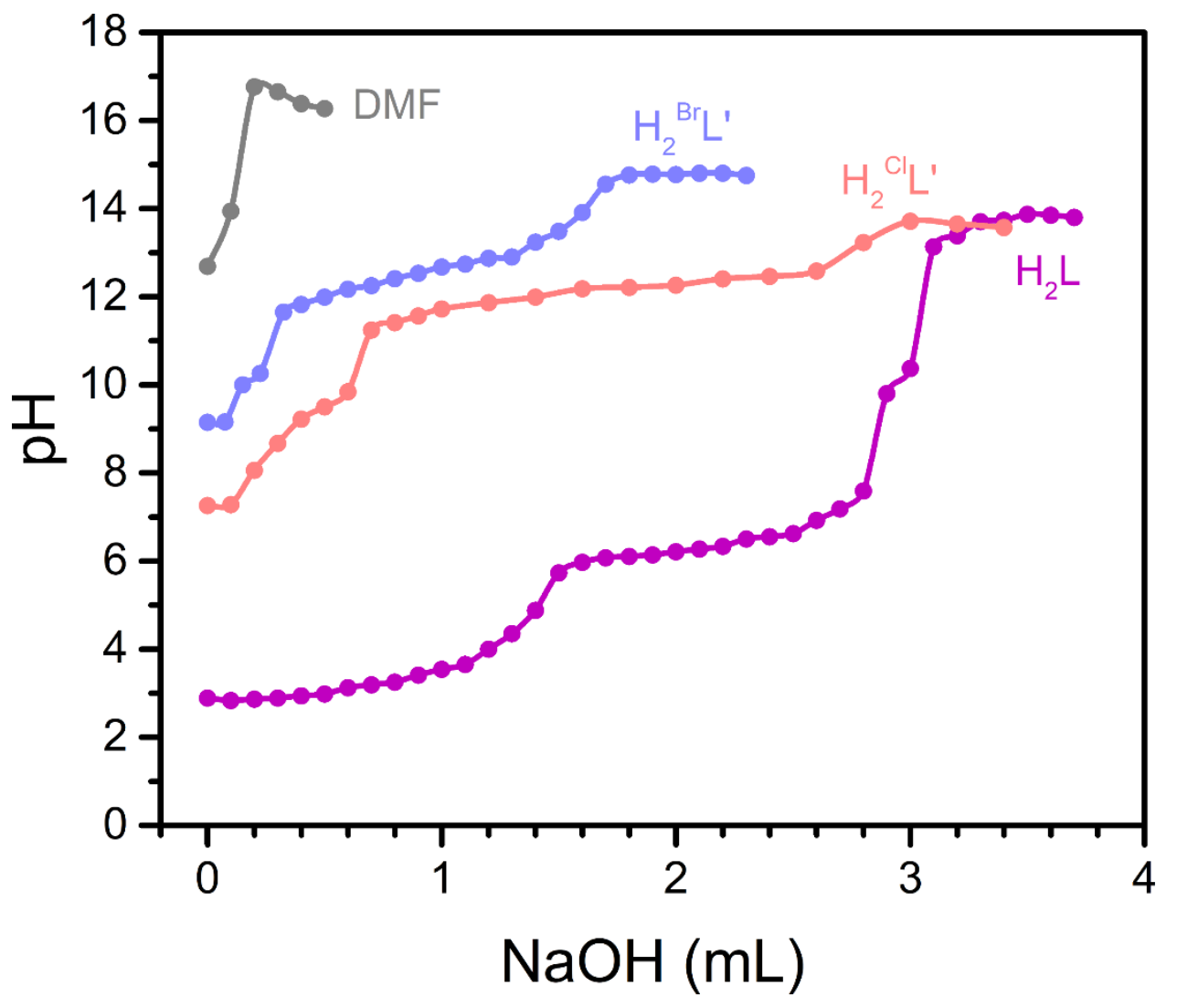

Figure S21. Acid-base titration curves for $\mathrm{H}_{2} \mathrm{~L}$ (purple), $\mathrm{H}_{2}{ }^{\mathrm{Br}} \mathrm{L}^{\prime}$ (blue), and $\mathrm{H}_{2}{ }^{\mathrm{Cl}} \mathrm{L}^{\prime}$ (pink). Blank curves are shown in gray. 


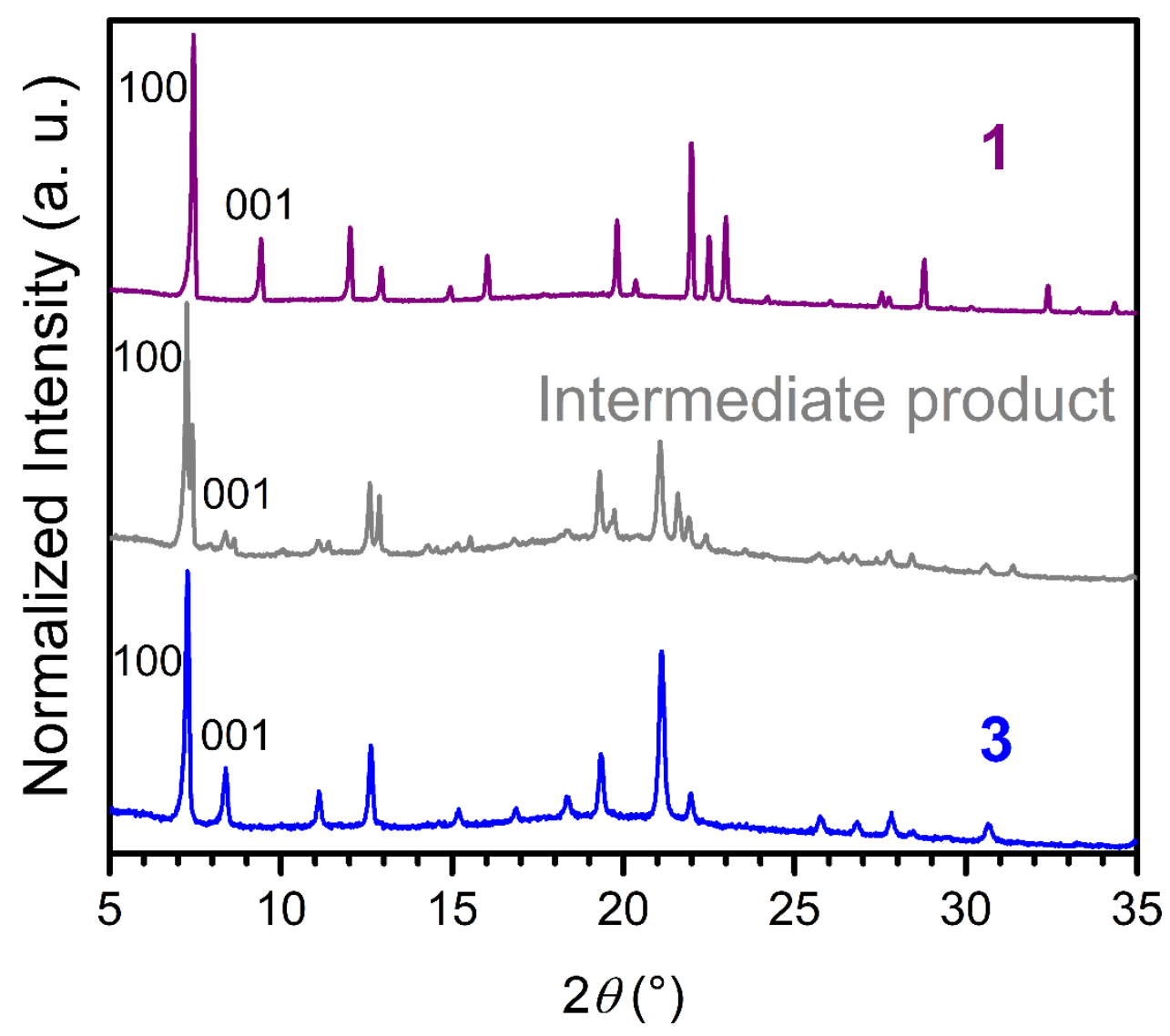

Figure S22. PXRD snapshot of an intermediate product (grey pattern) for the conversion from $\mathbf{1}$ (purple) to $\mathbf{3}$ (blue). 

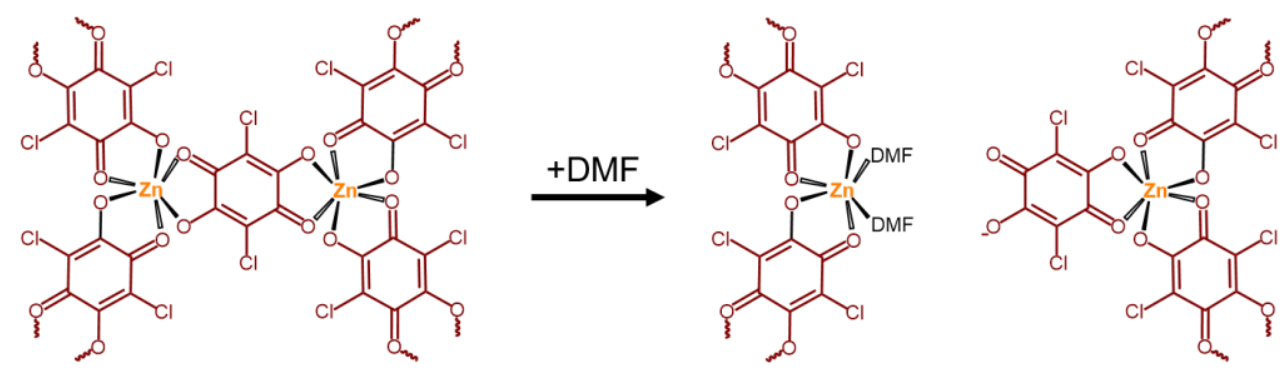

$$
\downarrow \begin{gathered}
+\left(\mathrm{Et}_{4} \mathrm{~N}\right)\left(\mathrm{H}^{\left.\mathrm{Cl} \mathrm{L}^{\prime}\right)}\right. \\
-\mathrm{DMF}
\end{gathered}
$$

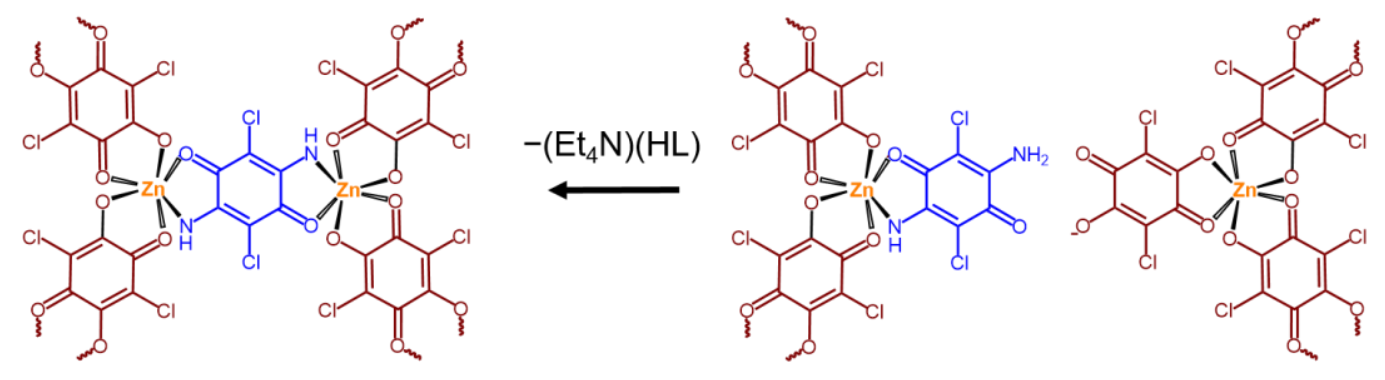

Figure S23. A proposed dissociative mechanism for linker exchange in 1. Following dissociation of $\mathrm{L}^{2-}$ from one $\mathrm{Zn}$ ion, singly deprotonated $\left(\mathrm{H}^{\mathrm{Cl}} \mathrm{L}^{\prime}\right)^{-}$coordinates to the solvated $\mathrm{Zn}$ ion. Subsequent dissociation and protonolysis of $\mathrm{L}^{2-}$ results in formation of a bridging $\mathrm{Zn}-\left({ }^{\mathrm{Cl}} \mathrm{L}^{\prime}\right)^{2-} \mathrm{Zn}$ moiety. Note that the increases in $\mathrm{Zn}-\mathrm{Zn}$ separations during the exchange are exaggerated for clarity. 


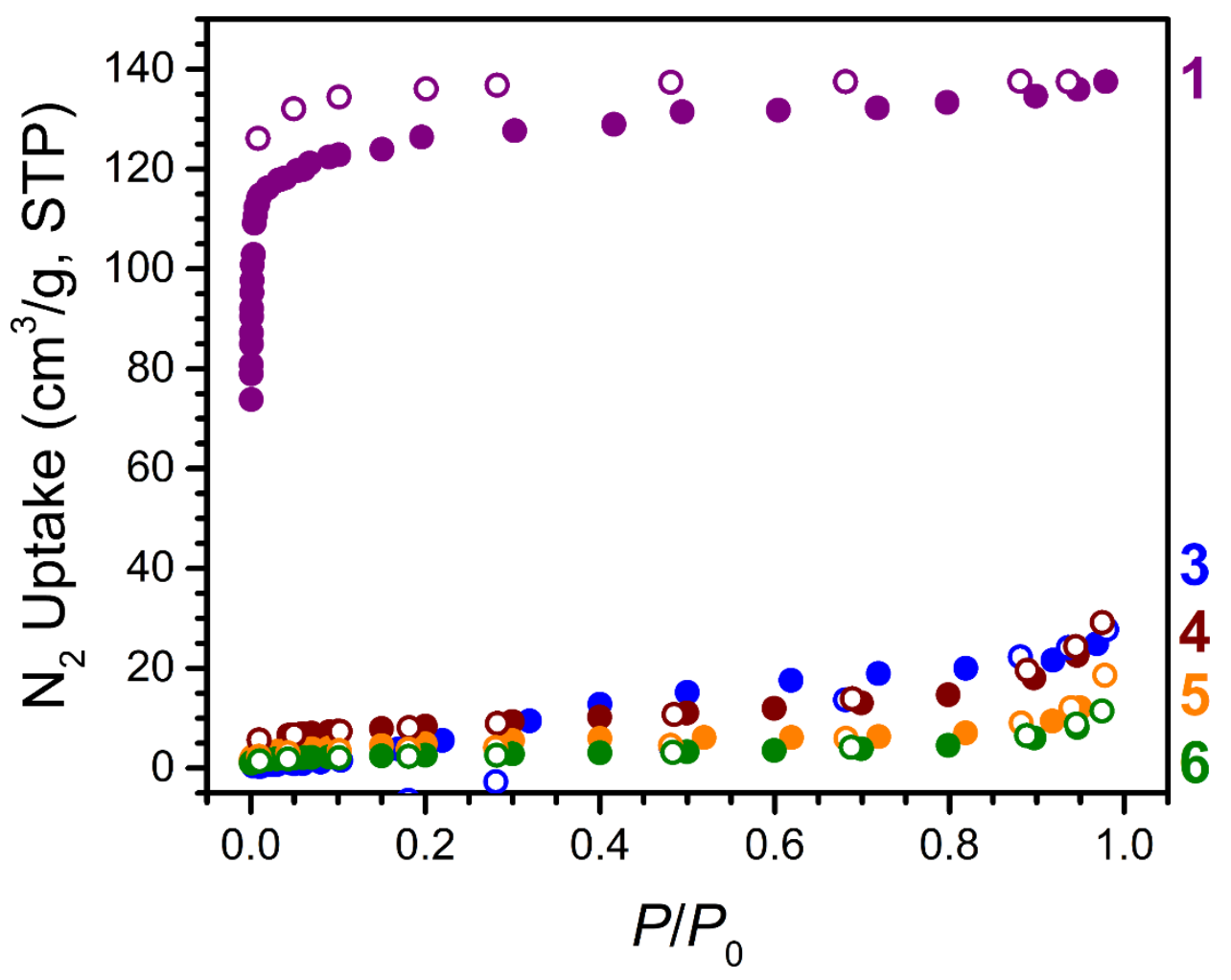

Figure S24. $\mathrm{N}_{2}$ adsorption (filled circles) and desorption (open circles) isotherms at $77 \mathrm{~K}$ for $\mathbf{1}$ (purple), $\mathbf{3}$ (blue), $\mathbf{4}$ (brown), $\mathbf{5}$ (orange), and $\mathbf{6}$ (green). 

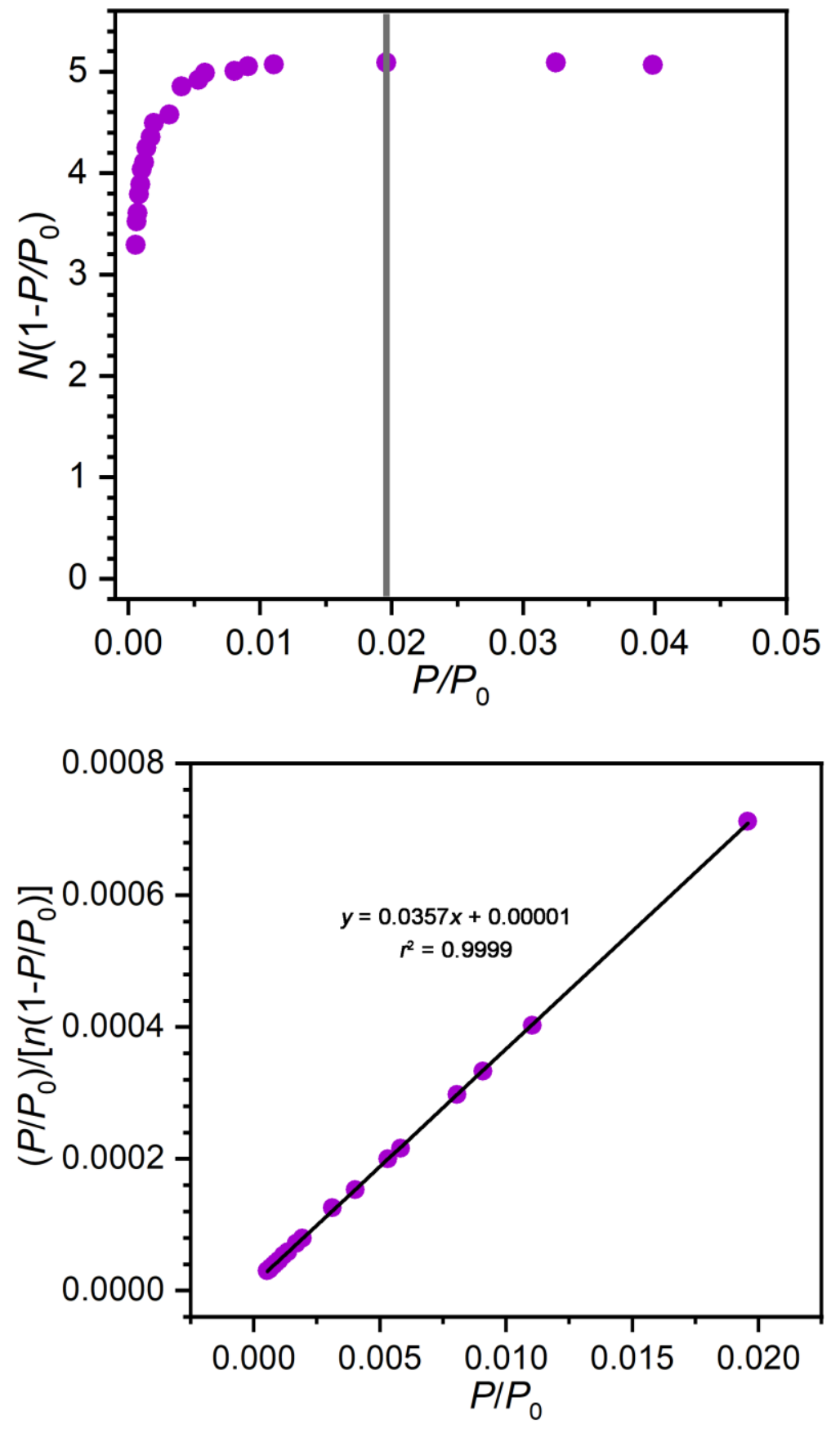

Figure S25. Consistency plots for calculating BET surface area of $\mathbf{1}$. This yields a surface area of $610 \mathrm{~m}^{2} / \mathrm{g} .{ }^{9}$ 


\section{References}

(1) Jeon, I.-R.; Negru, B.; Van Duyne, R. P.; Harris, T. D. J. Am. Chem. Soc. 2015, 137, 15699.

(2) Heqedus, L. S.; Odle, R. R.; Winton, P. M.; Weider, P. R. J. Org. Chem. 1982, 47, 2607.

(3) Inbasekaran, M.; Strom, R. Org. Prep. Proced. Int. 1991, 23, 447.

(4) APEX 3, v. 2016.1-0; Bruker Analytical X-Ray Systems, Inc: Madison, WI, 2016.

(5) Sheldrick, G. M. SADABS, version 2.03, Bruker Analytical X-Ray Systems, Madison, WI, 2000

(6) Sheldrick, G.M. XPREP, version 2008/2, Bruker Analytical X-Ray Systems, Inc., Madison, WI, 2008.

(7) Sheldrick, G. Acta Crystallogr. A 2008, 64, 112.

(8) Dolomanov, O. V.; Bourhis, L. J.; Gildea, R. J.; Howard, J. A. K.; Puschmann, H. J. Appl. Crystallogr. 2009, 42, 339.

(9) Walton, K. S.; Snurr, R. Q. J. Am. Chem. Soc. 2007, 129, 8552-8556. 